\title{
Environmental projects in the presence of corruption
}

\author{
Athanasios Lapatinas ${ }^{1,2}$ - Anastasia Litina ${ }^{2}$. \\ Eftichios Sophocles Sartzetakis ${ }^{3}$
}

\begin{abstract}
This paper establishes that in the presence of corruption, the implementation of technologically advanced environmental policies may result in lower environmental quality. In corrupt countries, politicians may allocate a large fraction of public funds to environmental projects with the intention of increasing their ability to extract rents, rather than improving environmental quality. This has both a direct and an indirect negative effect on environmental quality. First, due to extensive rent-seeking, the effectiveness of environmental projects is disproportional to the amount of public funds allocated to them. Second, citizens who observe the poor outcomes of environmental projects are more prone to tax evasion, which results in reduced public funds. A vicious circle of extensive tax evasion and rent-seeking activities thus emerges, which has a detrimental effect on environmental quality. Anecdotal evidence from a number of corrupt countries shows little or no improvement in environmental quality, despite the implementation of technologically advanced environmental projects.
\end{abstract}

Keywords Corruption · Environment · Technology

JEL Classification Q58 · D73

\footnotetext{
$凶$ Athanasios Lapatinas Athanasios.LAPATINAS@ec.europa.eu

1 European Commission DG Joint Research Centre, Via E. Fermi 2749, TP 361, 21027 Ispra, VA, Italy

2 University of Ioannina, Ioannina, Greece

3 University of Macedonia, Thessaloniki, Greece
} 


\section{Introduction}

Corruption in its various forms and expressions is a long-lasting phenomenon prevalent in both developed and developing countries, albeit to varying degrees of intensity. Its detrimental effects on a wide range of social and economic aspects including economic growth, education and the effectiveness of foreign aid, have been extensively analyzed. Moreover, the effect of corruption on the design and effectiveness of environmental policies have been explored, mainly with a focus on the role of lobbying groups in affecting the stringency of environmental policies and thus, environmental quality.

The present paper explores a different channel via which corruption can affect environmental quality. In particular, we argue that in countries experiencing high levels of corruption, politicians may allocate a large fraction of public funds to technologically advanced environmental projects with the aim of increasing their ability to extract high rents, rather than improving environmental quality. The behavior of these selfishly motivated politicians has two consequences: (i) decreasing the policies' effectiveness due to extensive rent-seeking, and (ii) reducing tax revenues, as citizens who observe the policies' poor outcomes are prone to tax evasion. Thus, the presence of widespread embezzlement leads to a vicious circle of extensive tax evasion and rent-seeking, with detrimental effects on environmental quality. Anecdotal evidence from a number of countries with high levels of corruption suggests that large investments in technologically advanced environmental projects do not yield improvements in environmental quality, thus lending credence to our theoretical hypothesis. ${ }^{1}$

There are two important assumptions embedded in our model that allow us to explore the effect of corruption on environmental quality. First, we emphasize the importance of the interaction between politicians and citizens. We assume that both groups' choices are driven by two conflicting types of incentives: to transfer highquality public goods to their offspring and to maximize their own consumption by engaging in corrupt activities. Specifically, taxpayers have the option to evade taxes, while politicians have the option to embezzle a portion of the tax revenue. ${ }^{2}$ We show that the two groups' common interest in their offspring's well-being results in an interaction between their decisions to engage in corrupt activities.

Second, following the literature, we assume that politicians' ability to extract rents is directly related to the level of technology employed in each type of public spending. The intuition is that more advanced technology involves less transparent expenditure, allowing the extraction of higher rents. Empirical evidence also confirms this argument, showing that public spending on more technologically advanced sectors

\footnotetext{
1 There are numerous mechanisms contributing to the paradoxical result that increased financing of environmental projects may lead to environmental degradation. The present paper focuses primarily on the behavioral drivers that we think are important, especially in countries in which weak institutions allow for widespread corruption. However, the mechanism developed in the paper incorporates also efficiency arguments.

2 In this paper, we adopt the term corruption both for rent-seeking activities and for tax evasion. Whereas there is a broad consensus as to the fact that embezzlement of public funds is a type of corruption, this is not the case for tax evasion. There is an ongoing debate as to whether tax evasion can be classified as corruption according to the term employed by the World Bank (the abuse of public office for private gain). For the sake of brevity, we abstract from this debate and adopt the term " corruption" for both activities.
} 
such as the military and the energy sector suffer from more widespread corruption in comparison with more labor-intensive sectors such as education. ${ }^{3}$ In order to simplify the analysis, we assume that politicians distribute the total tax revenue between environmental improvement projects (hereafter also called abatement activities) and an alternative public good such as education or public infrastructure. Specifying the type of alternative public good is not crucial for our argument. It is important, however, that spending on abatement and the alternative public good is associated with a differential ability to embezzle public funds. Although we are mainly interested in situations where environmental projects are more technologically advanced relative to the alternative public good, such as investments into renewables or carbon capture and storage projects, which are less transparent than spending on education, ${ }^{4}$ we examine the opposite case as well. For instance, an environmental project may involve reforestation, in which case the expenses are quite transparent relative to defense expenditures. To further simplify the analysis, we assume that the rates of rent-seeking associated with each of the two activities are fixed and exogenously given.

This framework allows us to focus on the strategic interactions between citizens who pay taxes and politicians who allocate public funds between the two types of activities. Whenever taxpayers observe politicians directing disproportionately higher levels of public funds to the high rent-seeking activity, they react by increasing tax evasion. On the contrary, whenever they observe politicians directing more resources to the activity associated with less rent-seeking, they respond by increasing their compliance. Crucially, the type of interaction between the two groups (i.e., strategic complementarity or substitutability), as well as the emerging equilibria, depend primarily on the level of technology used in each sector and the associated rent-seeking rates. Therefore, environmental quality at the equilibrium critically depends on the interaction between abatement technology and rent-seeking opportunities.

In order to derive analytical results, we develop a highly stylized model. However, a more elaborate model that relaxes important assumptions yields qualitatively similar results. The augmented version of the model is not fully tractable analytically, and thus we resort to numerical simulations. For presentation purposes, we relegate the presentation of this model to Appendix 2.

Our results have two important policy implications with respect to the effectiveness of environmental projects. First, corruption could result in substantial reductions in the public funds that are actually used to finance environmental projects. We identify both a direct and an indirect negative effect of corruption on the effectiveness of environmental projects. The direct effect is due to the fact that part of the funds allocated to environmental projects are diverted to corrupt politicians. The indirect effect is due to increased tax evasion, which leads to lower aggregate tax revenues, thus decreasing the public funds allocated to environmental projects. Second, in the presence of corruption, the implementation of technologically advanced environmental projects does not guarantee improvements in environmental quality. This is because advanced technologies are associated with greater embezzlement of public funds. Therefore,

\footnotetext{
3 See for example Gupta et al. (2000), Delavallade (2006) and Mauro (1998).

4 See Tanzi and Davoodi (1997, 2000) and Hessami (2010).
} 
strengthening the institutional system by improving transparency and reducing corruption is crucial for increasing tax revenues and allocating them efficiently among different activities.

The present paper relates to two strands in the literature. The first explores the effect of corruption on environmental quality. The majority of contributions uses a political economy approach and explores the effect of bureaucracy and lobbying groups on the stringency of environmental policy. Pashigian (1985) explains how competition among regions with different growth rates affects the stringency of regulations in these regions. Cropper et al. (1992) and Helland (1998) report the effect of environmental interests on political and budget considerations on the US Environmental Protection Agency (US EPA) regulations. Lopez and Mitra (2000) examine the effect of corruption and rent-seeking on the relationship between pollution and growth and on the shape of the environmental Kuznets curve. Damania (2002), Damania et al. (2004) and Stathopoulou and Varvarigos (2013) develop theoretical models that analyze bureaucratic corruption in situations where the implementation of environmental policy requires inspection and emission monitoring by public officials. Fredriksson et al. (2003) examine the effect of corruption and rent-seeking on US FDI, on the stringency of environmental policy and the pollution haven hypothesis. ${ }^{5}$ Lisciandra and Migliardo (2017) empirically establish first that corruption deteriorates environmental quality and second that increases in income lead to an increase in environmental quality. In our paper, we theoretically explore a different channel through which the effect of corruption on environmental quality may take place, i.e., via rent-seeking opportunities associated with investment in environmental projects. ${ }^{6}$

Second, we build upon the literature exploring the interactions among different societal groups. We argue that politicians' corrupt behavior may trigger non-compliance on behalf of citizens, leading to the reduction of total public revenues. This suggests that corruption seems to be contagious, or as Andvig and Moene (1990) put it "corruption may corrupt". Tanzi and Davoodi (2000) investigate the relationship between levels of corruption (measured by corruption perception indices) and GDP in a sample of 97 countries and find that higher corruption is consistent with lower revenues of all types of taxes, especially income taxes. Whenever taxpayers feel that politicians are corrupt or that their burden is not fair compared to others they choose to become more corrupt as well. Litina and Palivos (2013) associate the current economic crisis in Greece with corrupt activities of different societal groups and their interaction. A recent paper related to the justification of 'behavioral' point/mechanism is Gächter and Schulz (2016) in 'Nature'. In a cross-cultural experiment involving 2568 individuals in 23 countries, the authors show that prevalence of rule violations in a society, such as tax evasion and fraudulent politics, is detrimental to individuals' intrinsic honesty. In other words, the authors address the behavioral/psychological drivers of corruption with an experiment involving finding that corruption corrupts. The study shows that

\footnotetext{
5 For empirical evidence showing that environmental quality is positively affected by the quality of institutions see also Bhattarai and Hamming (2001), Bimonte (2002), Panayotou (1997) and Torras and Boyce (1998).

6 One could consider other types of intervention other than investment in environmental projects, such as, e.g., regulation for tradeable permits(see, e.g., Antoniou et al. 2014).
} 
the price of corruption for society goes deeper than purely financial, and can have a psychological impact. People take the ethics of government or big businesses as role models, and their cheating acts as a bad example for dishonest practices: if politicians are corrupted then this behavior goes down into the general population. ${ }^{7}$

Section 2 of the paper provides some anecdotal evidence that motivates our findings. Section 3 introduces the benchmark model. We resort to a simple framework that allows us to obtain analytical results. Section 4 concludes the paper. Appendix establishes the robustness of our theoretical results by employing a set of more realistic assumptions. As some of these assumptions increase the complexity of the model we resort to numerical simulations to show that it could yield qualitatively similar predictions.

\section{Anecdotal and empirical evidence}

One of the major problems associated with tracing corrupt activities is that they take place secretly and come to the surface only if they are revealed and investigated. This is particularly true in the case of illegal activities associated with environmental policy. Two main reasons can account for this fact. First, it is only in the last few decades that large environmental projects have been undertaken, and therefore corruption activities associated with these are also a relatively new phenomenon. Second, the technology associated with these projects is rather advanced and it is therefore even more difficult to identify instances of corruption, due to the less transparent nature of these activities.

Three examples are cited in this section: (i) The Lesotho Highlands Water Project (LHWP); (ii) The SISTRI Project and, (iii) The Toxic Scandal in Kalush.

\subsection{Lesotho Highlands Water Project, Lesotho}

The Lesotho Highlands Water Project (LHWP) was initiated in 1986 through an agreement between the governments of Lesotho and South Africa and was, at the time, the most extensive international water transfer project in the world. Its aim was to provide water to Johannesburg by diverting it from the Orange river to the Vaal river. In addition, the project was supposed to generate royalties from water sales and hydroelectric power for Lesotho. The agreement dedicated resources to the development of rural areas in Lesotho, the compensation of the displaced and amendments to the areas affected by the project. The implementation of the project required the development of a number of dams and tunnels, and the estimated cost of the project was more than $\$ 8$ billion. As the project expanded across a large area, the benefits associated with it came with substantial environmental costs to nearby communities. A significant part of the project's cost was related to the development of a social fund aimed at mitigating the environmental consequences. During the first phase of the project, four dams and $110 \mathrm{~km}$ of tunnels were constructed.

\footnotetext{
7 See also the discussion in Shalvi (2016) and the article in 'The Telegraph' entitled 'Britain has most honest citizens in the world... because politicians are less corrupt' (http://www.telegraph.co.uk/news/ science/science-news/12189003/Britain-has-most-honest-citizens-in-the-world...-because-politiciansare-less-corrupt.html)].
} 
Today, the project remains largely unfinished, the expected benefits have not been realized, and extensive environmental degradation has occurred. The delay is due to a number of corruption scandals related to the project. In 1999, the Chief Executive of the Lesotho Highlands Development Agency was accused of corruption and twelve companies were accused of offering huge bribes to win various contracts. After the agency's chief executive was found guilty, three major European companies were also found guilty and charged, and one Canadian firm has been debarred by the World Bank. These actions resulted in the inefficient management of the project's funds, raising both the financial cost and the environmental burden. As a result, the project's second phase was delayed and was initiated only very recently (March 2014) amidst concerns about the likelihood of corruption in tender processes.

\subsection{The SISTRI project, Italy}

In 2009 the Italian Ministry of Environment launched an information system, SISTRI, aimed at unifying the waste management services at the national level and improving the urban waste management at the Campania region. The implementation of the system was expected to yield substantial environmental improvements through the deterrence of illegal waste dumping and significant cost reductions. The estimated cost of the project was about 400 million euros and involved highly sophisticated technology that would ensure the achievement of the ambitious goals. Nevertheless, a large part of the funds were collected by the companies via non-transparent procedures without any advancement of the project. A large scandal emerged involving bribes, embezzlement of the funds and a number of other illegal activities. The project's launch date was postponed twice before being abolished in August 2011. A number of people have been persecuted, among them government officials and a member of the parliament. More recently (March 2014), two former managers of Finmeccanica SpA, Italy's state-controlled defense and industrial group, have also been arrested over allegations of international corruption in relation to the SISTRI project.

\subsection{The toxic scandal in Kalush, Ukraine}

For more than three decades, between 1967 and 2001, large amounts of the industrial chemical hexachlorobenzene, or HCB, were used in an open-pit mine that was part of the state-owned Oriana chemical enterprise in Ukraine. This highly toxic, cancercausing chemical, banned worldwide by the Stockholm Convention, is seeping into groundwater and the tributaries of the Dniester River, a source of water for some 10 million people in western Ukraine and Moldova.

In 2010, a decree by the Ukrainian government declared the region to be an ecological disaster zone and allocated several hundred million hryvnia (the local currency, $1.00 \mathrm{USD}=21.8 \mathrm{UAH}$ ) to resolve the problem. In August 2013, the Department of Construction, Housing, Urban Development and Architecture of the Ivano-Frankivsk Regional State Administration held a public procurement procedure for disposal services at the Kalush landfill. The bidding was won by “S.I. Consort Group Ltd.”, despite 
accusations that the company did not possess the proper license to perform hazardous waste operations.

Following the completion of the project, a number of studies testing samples of soil and water taken from the reclaimed Kalush landfill reported extremely high concentrations of HCB. In 2014, regional prosecutors announced the opening of criminal proceedings on the grounds of large-scale appropriation, and embezzlement or the acquisition of another's property through malpractice. Local and international environmental groups are demanding an independent international investigation of abuses by officials and companies involved in the project, since they fear that it may take a decade for regional authorities to investigate criminal proceedings, while enterprises with no permits or production capacity continue "cleaning" areas in Ukraine. ${ }^{8}$

\section{The benchmark model}

Consider a perfectly competitive overlapping generations economy where economic activity extends over infinite discrete time and a single good is being produced in the private sector. Individuals live for two periods, i.e., childhood and adulthood. During the first period of their life individuals acquire human capital via public schooling, whereas during adulthood they either enter the productive sector of the economy or they become politicians via a random selection process. Their preferences are defined in regards to their own consumption, as well as the well-being of their offspring, which is captured by the level of human capital and the quality of the environment bequeathed to them. ${ }^{9}$ For expositional convenience, we assume that the two public goods are abatement and education. As mentioned above, the only crucial point is that spending on each public good provides differential opportunities for rent-seeking.

Moreover, while the issues of corruption and embezzlement may have international implications, as the anecdotal evidence presented in Sect. 2 suggests, in our model we deal with a closed economy in order to restrict our focus to the mechanism we advance.

\subsection{The structure of the economy}

In each period $t$, a generation of individuals of measure one is born. Each individual has a single parent. During childhood individuals acquire human capital and for simplicity, it is assumed that they are not economically active; their consumption is incorporated into their parents' consumption. During adulthood individuals are economically active

\footnotetext{
8 See for example the news reports: http://epl.org.ua/en/events/969-epl-is-presenting-its-studiesof-the-problem-in-kalush-with-removal-of-hexachlorobenzene-or-how-ukraine-s-territory-is-cleanedusing-budget-funds and http://www.kyivpost.com/content/ukraine/toxic-waste-toxic-scandal-in-kalush353646.html, accessed on 12-08-2015.

9 Environmental quality affects offspring's well-being either directly, e.g., they simply gain utility from a clean environment, as we assume in this version of the model, or both directly and indirectly via affecting production as well. The latter case where environmental quality is an input to the production process is explored in the more elaborate version of the model presented in Appendix. As shown, in both cases it is not a crucial assumption that can alter our qualitative results.
} 
allocating their income between current consumption and their offspring's well-being. Formally, individuals born at $t-1$, during their adulthood (i.e., in period $t$ ), maximize the following utility function,

$$
u_{t}=c_{t}\left(h_{t+1}+Q_{t+1}\right) \text {, }
$$

where $c_{t}$ denotes the adults' level of consumption, $h_{t+1}$ is their offspring's human capital and $Q_{t+1}$ is the environmental quality handed over to their offspring. The presence of the offspring's human capital level and environmental quality in the parental utility function captures the adult agent's vested interest in publicly funded education and environmental (abatement) projects. ${ }^{10}$ The choice of this particular functional form, where the elements human capital and environmental quality enter additively, allows us to introduce the trade-off that exists in allocating resources between the environment (i.e., abatement) and education. ${ }^{11}$

Following the literature, we assume that the learning technology is described by, ${ }^{12}$

$$
h_{t}=\tilde{H} H_{t-1}-v H_{t-1}+B E_{t-1},
$$

where $t$ denotes time, $h_{t}$ is the level of human capital acquired by an individual born at $t-1, H_{t-1}$ is the average stock of human capital present in the economy at time $t-1$, and $E_{t-1}$ is the public spending on education in the same period. According to this human capital accumulation process, a young agent born in period $t-1$, can pick up a fraction $\tilde{H} \in[0,1]$ of the existing (average) level of human capital $H_{t-1}$ without any cost, simply by observing what the previous generation does. Existing human capital depreciates at a rate $v \in[0,1]$. To further enhance an agent's human capital requires the allocation of public resources to education, $E_{t-1}$. The parameter $B>0$ measures the efficiency of the public education system. Therefore, the overall level of human capital reflects the effect of both societal knowledge and formal education.

The evolution of environmental quality is described by,

$$
Q_{t}=Q_{0} H_{t-1}-\psi H_{t-1}+A \Pi_{t-1}, \quad Q_{0}>\psi,
$$

where $Q_{0} H_{t-1}$ denotes the initial state of environmental quality $Q_{0}$, conditional on the level of production $H_{t-1}$ in period $t-1$. The term $\psi H_{t-1}$ captures the environmental damage caused by production in the previous period (we assume that production employs only human capital), and $\psi$ is a technological parameter that can be interpreted as the rate of environmental degradation per unit of output. The term $A \Pi_{t-1}$ captures

10 The introduction of a parameter measuring the relative strength of the altruistic motive associated with each activity would further complicate our analysis without providing additional insights. Similarly, assuming an additive type of utility function (with respect to $Q_{t}$ and $H_{t}$ ) is also for the sake of analytical convenience.

11 This type of aggregate production function is used in various contexts, as well as in the context of environmental economics. For example, in Grimaud and Tournemaine (2007) individuals derive utility from the consumption of goods, their level of education, and a clean environment where all variables are additively included in the utility function.

12 See for example De Gregorio and Kim (2000) and Ceroni (2001). 
the beneficial effect of publicly funded abatement activities on environmental quality, where $A$ is a technological parameter. ${ }^{13}$

Assuming that environmental quality depends on human capital is adopted primarily for analytical convenience. Importantly though, as suggested by empirical and theoretical evidence, human capital is correlated with environmental quality and higher abatement due to the fact that more educated people and societies are in a better position to impose and implement environmental policies. ${ }^{14}$

\subsection{Citizens and politicians}

Individuals entering into adulthood are, via a random process, either employed in the productive sector (hereafter called citizens) or they become politicians. Individual preferences are independent of occupation. For analytical convenience, it is assumed that there is a continuum of agents within each group that is normalized to unity. In terms of notation, the subscripts $c$ and $p$ are used to denote variables that are related to citizens and politicians, respectively.

13 It is clear that the definition of the evolution of environmental quality in Eq. (3) is less plausible since the assumption $Q_{0}>\psi$ suggests that, even if we remove pollution abatement, the overall effect of production on environmental quality is positive. We choose to make this simplifying assumption, in order to derive analytical solutions and provide clear intuition for our results. In Appendix 2, we show that the same results are obtained under a more plausible framework, which though does not allow the derivation of analytical solutions. Although we acknowledge that our simplifying assumptions reinforce our main result, they also allow us to show in a clear and simple way how rent-seeking activities can have a detrimental effect on environmental quality. We elaborate further on the implications of these assumptions following Proposition 2 that states the paper's main result.

14 The link between environmental quality and human capital has been empirically and theoretically analyzed in different contexts. Goetz et al. (1998), Carlsson and Johansson-Stenman (2000) and Brock and Taylor (2005) highlight the important role played by socio-demographic and economic factors, in explaining the relationship between the level of education and environmental quality. More specifically, Goetz et al. (1998) show that environmental quality is higher in the USA where the proportion of agents who have a high school degree is large. Higher human capital allows individuals to perceive the costs and the benefits of achieving better environmental conditions (See also Kahn 2002; Fredriksson et al. 2005; Farzin and Bond 2006).

The link between human capital and environmental quality is also captured through the analysis of the "green" vote. Thalmann (2004) and Bornstein and Lanz (2008), using data from a Swiss referendum on green taxes, show that the acceptance and approval of green taxes is higher among educated agents. Furthermore, Raffin (2010), using data from the Center for International Development (CID) on the secondary school enrollment in 2000 and the Environmental Performance Index (EPI) shows a positive correlation between the two variables and develops a model of political economy that captures the fact that more educated economies display better environmental performance.

In the context of firms, Lan and Munro (2013) show that within the firms, the implementation of abatement technologies is determined by the absorptive capacity of internal human capital endowment: the higher the level of human capital, the better the application within the firm. Empirical studies find that firms with more human capital are more likely to adopt new technologies of abatement and have better environmental performance (Pargal and Wheeler 1996; Dasgupta et al. 2000; Gangadharan 2006; Manderson and Kneller 2012; Blackman and Kildegaard 2010).

Theoretically, a series of papers have adopted specifications that link human capital with environmental quality. For instance, Raffin (2010) and Ikefuji and Horii (2007) are assuming human capital as the only input of production to capture the greater capacity of educated employees to adopt and apply an advanced technology (see, e.g., Fershtman et al. 1996; Caselli 1999; Galor and Moav 2000). 
Citizens produce a single good consumed by both groups. In the baseline version of the model, we assume that production employs only human capital, while the environment does not contribute to the production process. ${ }^{15}$ Thus, using the appropriate normalization of units, each citizen's output $y_{t}$ is, ${ }^{16}$

$$
y_{t}=h_{t} \text {. }
$$

It follows that the aggregate production function is linear to the aggregate level of human capital, that is, $Y_{t}=H_{t}$. Notice that since the size of each group is normalized to one, $h_{t}=H_{t}$ and thus, $y_{t}=Y_{t}$.

Taxing citizen's income at the rate $\tau$, assumed to be exogenous and time-invariant, provides the necessary revenue for the provision of public education and abatement. Citizens have the option to evade a fraction of their taxes and thus they can decide upon the fraction $z_{t}$ of their income that is declared to the tax authority. For the sake of brevity it is assumed that the citizen's declaration is never audited; consequently, tax evasion does not involve any risk. Although tax payments are implicitly assumed to be a voluntary contribution, citizens' incentive to free ride is partly mitigated by their altruistic concerns about their offspring's education and environmental quality and thus, they always declare a positive fraction of their income, as will be illustrated later. ${ }^{17,18}$

Politicians do not participate in the production process. Instead, their role lies in determining the allocation of public funds between education (a fraction $\varphi$ of the total tax revenue) and abatement. The politician receives a fixed income, as a reimbursement for her service, which for analytical convenience and without loss of generality is assumed to be equal to zero. Moreover, she has the option to embezzle part of the total tax revenue as a means of supplementing her income. ${ }^{19}$ Specifically, she can embezzle a fraction $\left(1-\omega_{q}\right)$ of public funds directed to abatement, and a fraction $\left(1-\omega_{h}\right)$ of the funds earmarked for education. It is assumed that both $\omega_{q}$ and $\omega_{h}$ are exogenously given, strictly positive and less than one. The magnitude of the $\omega^{\prime} \mathrm{s}$

15 The robustness to this assumption is tested in the more elaborate version of the model in Appendix 2, where we assume that environmental quality is also an input to the production process.

16 Since all agents have the same level of human capital we omit the subscript $i=c, p$.

17 This also implies that adding the possibility of auditing and the subsequent fines would not qualitatively affect the main results, it would only affect the scale of the effect. In Appendix 1, we illustrate a modified version of the model with a positive probability of being audited and therefore caught. As shown in Appendix, our qualitative results remain intact.

18 Still, citizens find it optimal to evade a fraction of their income. Alternatively, we could construct a model where there are two different types of citizens and two different types of politicians who differ in their corruption attitude (e.g., differential tax morale). This would allow us to address the issue of free riding more explicitly. Such an approach, extends beyond the scope of our analysis, however weakening the main argument that higher investment in abatement may result in the deterioration of environmental quality. The issue of free riding, while it could affect the quantitative characteristics of our findings, is not the driving force behind our results.

19 Assuming a positive reimbursement for the politician (either a constant amount, or a fraction of the tax revenue) reduces the magnitude of the incentive to embezzle public funds, but it does not qualitatively affect the results. As long as there is an incentive to embezzle a portion of the funds, the results of the model remain robust to this assumption. 
depends on the economy's institutional, political and social characteristics, whereas their relative magnitude, i.e., whether $\omega_{q} \gtrless \omega_{h}$, depends on the public activity's characteristics. In the context of the paper, we do not endogenize the choice of $\omega^{\prime} \mathrm{s}$ as this extends beyond the scope of our analysis. ${ }^{20}$ What is crucial for our analysis is the plausible assumption that different sectors of the economy manifest differential rent-seeking rates.

For instance, one could argue that $\omega_{h}>\omega_{q}$, since education mainly involves transparent transactions, such as wages and equipment that are not overly technologically advanced. It is therefore associated with low rates of rent-seeking. On the other hand, abatement technology can be rather sophisticated and thus, its implementation less transparent. As suggested by Tanzi and Davoodi (1997), the more technologyintensive is an activity, the less susceptible it is to the scrutiny of citizens, and thus the higher the level of rent-seeking associated with it. However, rent-seeking rates related to environmental projects can vary significantly depending on the type of abatement technology. For example, reforestation involves much less sophisticated technology and is thus a much more transparent activity than investment in renewables. In order to be able to discuss the choice between environmental policy and other types of public policy, we allow the relative magnitude of $\omega^{\prime}$ s to vary. We assume that the politician is aware of the values of $\omega_{q}$ and $\omega_{h}$ before allocating the available public funds between the two activities.

We further assume that the politician is never investigated and hence peculation does not involve any risk. Given that the politician has zero income, she will always embezzle a fraction of the tax revenue. However, the politician's concern over her offspring's well-being implies that she has an incentive to avoid directing the entire amount of public funds to the activity with the higher rent-seeking rate. ${ }^{21}$

Since only citizens are being taxed, the total tax revenue $R_{t}$, collected in period $t$, is the fraction of the aggregate income that is being declared and therefore taxed, i.e., $R_{t}=z_{t} \tau h_{t} . h_{t}$ is the gross income of the citizen in period $t$ which is taxed at the exogenous rate $\tau$. The citizen chooses the fraction $z_{t}$ of his income to declare to the tax authorities and pays income tax $\tau z_{t} h_{t}$. In the absence of embezzlement by the politician, a fraction $\varphi_{t} z_{t} \tau h_{t}$ of the tax revenue would be earmarked for education and the remaining $\left(1-\varphi_{t}\right) z_{t} \tau h_{t}$ for abatement.

However, the politician peculates a fraction of this revenue. In particular, she peculates a fraction $1-\omega_{h}\left(1-\omega_{q}\right)$ of the tax revenue earmarked for education (abatement), and thus, the actual amount spent on education $E_{t}$ (abatement $\Pi_{t}$ ) is,

$$
\begin{aligned}
E_{t} & =\varphi_{t} \omega_{h} z_{t} \tau h_{t}, \\
\Pi_{t} & =\left(1-\varphi_{t}\right) \omega_{q} z_{t} \tau h_{t},
\end{aligned}
$$

\footnotetext{
20 There is an extensive literature focusing on the implications of rent-seeking rates (see, e.g., Krueger 1974; Park et al. 2005; Angelopoulos et al. 2009).

21 Similarly to the case of the citizen, as long as the politician has an incentive to direct part of the funds in both activities, enriching the model with a probability to be caught and punished would increase the complexity of the model without adding further insights (see Appendix).
} 
respectively. Overall, individuals' decisions at time $t$ regarding the level of tax evasion and the allocation of public funds, have an indirect effect on the aggregate level of both public goods which is enjoyed by the offspring of both types of individuals. Therefore, citizens' decisions are indirectly affected by the decisions of the politicians and vice versa, driven by the altruistic incentives of both groups, thus suggesting the presence of strategic interactions in their decision-making process.

\subsection{Optimization}

\section{Citizen}

As discussed above, a citizen's preferences are defined over his own consumption in period $t, c_{c t}$, and his offspring's well-being in the next period $t+1$ as affected by the level of human capital they will acquire $h_{t+1}$, and the quality of the environment $Q_{t+1}$. His gross income in period $t$ is $h_{t}$, which is taxed at the exogenous rate $\tau$. The citizen chooses the fraction $z_{t}$ of his income to declare to the tax authorities and pays income tax $\tau z_{t} h_{t}$, which implicitly determines consumption at time $t$ and the level of public goods transferred to his offspring. ${ }^{22}$ We assume that citizens cannot directly observe the politicians' ability to embezzle part of the total tax revenue. He indirectly observes politicians' actions via the environmental and educational quality of the next period, which is crucial for the well-being of the citizen's offspring. Therefore, each citizen solves the following optimization problem,

$$
\begin{aligned}
& \max _{c_{c t}, z_{t}} c_{c t}\left(H_{t+1}+Q_{t+1}\right), \\
& \text { subject to } c_{c t}=\left(1-z_{t} \tau\right) h_{t}, \\
& c_{c t} \geq 0, \quad 1 \geq z_{t} \geq 0,
\end{aligned}
$$

where $h, Q, E$ and $\Pi$ are determined by Eqs. (2), (1.5) and (5).

Maximization yields the citizen's choice of $z_{t}$ as a function of the model's parameters and the politician's choice of $\varphi$. Thus, we get the citizen's best response function to the politician's choice of $\varphi$,

$$
z_{t}=f\left(\varphi_{t}\right)=\frac{\left(A \omega_{q}-\varphi_{t} \Omega_{T}\right)-\Psi}{2 \tau\left(A \omega_{q}-\varphi_{t} \Omega_{T}\right)},
$$

where $\Omega_{T}=A \omega_{q}-B \omega_{h}$ and $\Psi=Q_{0}+\tilde{H}-\psi-v$. The second-order condition, ensuring concavity, requires that $A \omega_{q}-\varphi_{t} \Omega_{T}>0$, which always holds since $\varphi_{t} \leq 1$.

Furthermore, an interior solution $(1>z>0)$ exists iff $(1-2 \tau)\left(A \omega_{q}-\varphi_{t} \Omega_{T}\right)<$ $\Psi<A \omega_{q}-\varphi_{t} \Omega_{T}$. On the contrary, a corner solution will emerge if $\Psi \geq\left(A \omega_{q}-\right.$ $\left.\varphi_{t} \Omega_{T}\right)\left(z_{t}=0\right)$ or $\Psi \leq(1-2 \tau)\left(A \omega_{q}-\varphi_{t} \Omega_{T}\right)\left(z_{t}=1\right)$.

To gain more intuition, we rewrite the reaction function as $z_{t}=f\left(\varphi_{t}\right)=\left(A \omega_{q}(1-\right.$ $\left.\left.\varphi_{t}\right)+\varphi_{t} B \omega_{h}\right)-\Psi / 2 \tau\left(A \omega_{q}-\varphi_{t} \Omega_{T}\right)$. We can now highlight the following: For the reaction function to take positive values it is essential that the numerator takes positive

22 Consumption at time $t$ equals the citizen's disposable income $(1-\tau) z_{t} h_{t}+\left(1-z_{t}\right) h_{t}=\left(1-z_{t} \tau\right) h_{t}$. 
values, i.e., $\left.A \omega_{q}\left(1-\varphi_{t}\right)+\varphi_{t} B \omega_{h}\right)-\Psi>0$. This implies that the educational and environmental output that is delivered by policy (always taking into account the actions of the other group, i.e., the allocation $\varphi_{t}$ to each activity as determined by the politician), i.e., $\left.A \omega_{q}\left(1-\varphi_{t}\right)+\varphi_{t} B \omega_{h}\right)>\Psi$, where $\Psi=Q_{0}+\tilde{H}-\psi-v$ reflects the educational and environmental output that is obtained without the use of any funds. Interestingly, an interior solution is likely to emerge when the following occurs: if the associated technologies are effective, i.e., if $A$ and $B$ take large values, if rent-seeking is small, i.e., if $\omega_{q}$ and $\omega_{h}$ take large values, and if the allocation of resources is favouring the most efficient activity, that is, when public resources are used quite effectively. If the difference is too big [i.e., if $\left(A \omega_{q}\left(1-\varphi_{t}\right)+\varphi_{t} B \omega_{h}\right)-\Psi / 2 \tau\left(A \omega_{q}-\varphi_{t} \Omega_{T}\right)>1$ ] due to either the effective use of public resources or due to the fact that the increase in human capital and environmental quality without the use of public funds is very low (i.e., very low $\Psi$ ), then both citizens and politicians have an incentive to choose a corner solution in which they will evade/embezzle a minimum amount of money, if at all. On the contrary if the increase in human capital and of environmental quality without the use of public funds is very high (i.e., very high $\Psi$ ), such that $\left.A \omega_{q}\left(1-\varphi_{t}\right)+\varphi_{t} B \omega_{h}\right)-\Psi<0$ then citizens and politicians are less incentivized to direct money to public education and abatement and will choose the high corruption/embezzlement equilibrium.

Comparative statics suggest that when $v$ and $\psi$ increase, i.e., when there is extensive depreciation of environmental quality and human capital, citizens choose a lower rate of tax evasion. On the contrary when $Q_{0}$ and $\tilde{H}$ increase, then $z_{t}$ decreases suggesting that citizens declare a smaller part of their income to tax authorities. Lemma 1 presents the comparative statics with respect to technology and policy parameters.

Lemma 1 Whenever an interior solution emerges, the tax evasion rate $\left(1-z_{t}\right)$ is reduced:

i. the more efficient is the use of tax revenues, (i.e., the higher are A and B),

ii. the lower are the rent-seeking rates (i.e., the higher $\omega_{q}$ and $\omega_{h}$ ), and

iii. the lower is the tax rate, $\tau$.

Proof The above results can be obtained by taking the derivatives of the interior solution with respect to each parameter.

The intuition of all three parts of Lemma 3 is straightforward and expected. Citizens do appreciate the efficient use of their taxes, when tax rates are reasonable and rentseeking activities are controlled. As they observe the occurrence of any or all of them, they are willing to contribute more to public funds.

\section{Politician}

Since we have assumed that individual preferences are independent of occupation, politician's preferences are also given by (1). Assuming zero income from other sources, the politician derives income only via the embezzlement of public funds. Taking as given the rent-seeking rate associated with education $1-\omega_{h}$, and abatement $1-\omega_{q}$, she determines the allocation of public revenues between the two activities in order to maximize her utility. Her income equals the sum of the funds embezzled from the education and abatement activities, i.e., $\left(1-\varphi_{t}\right)\left(1-\omega_{q}\right) \tau z_{t} H_{t}+\varphi_{t}\left(1-\omega_{h}\right) \tau z_{t} H_{t}$. 
The politician solves the following optimization problem with respect to the fraction of revenue that will be allocated in each activity $\varphi_{t}$,

$$
\begin{aligned}
& \max _{c_{p t}, \varphi_{t}} c_{p t}\left(H_{t+1}+Q_{t+1}\right), \\
& \quad \text { subject to } c_{p t}=\left[\left(1-\varphi_{t}\right)\left(1-\omega_{q}\right)+\varphi_{t}\left(1-\omega_{h}\right)\right] \tau z_{t} h_{t}, \\
& c_{p t} \geq 0, \quad 1 \geq \varphi_{t} \geq 0,
\end{aligned}
$$

where $h, Q, E$ and $\Pi$ are determined by Eqs. (2), (1.5), (5) and (6).

The first-order condition of (9) yields the politician's best response function to citizen's choice of $z_{t}$,

$$
\begin{aligned}
\varphi_{t} & =g\left(z_{t}\right) \\
& =\frac{\Psi \Omega-\tau z_{t}\left[\left(1-\omega_{q}\right) \Omega_{T}-A \omega_{q} \Omega\right]}{2 \tau z_{t} \Omega_{T} \Omega} \\
& =\frac{\Psi}{2 \tau z_{t} \Omega_{T}}-\frac{\left(1-\omega_{q}\right) \Omega_{T}-A \omega_{q} \Omega}{2 \Omega_{T} \Omega},
\end{aligned}
$$

where $\Omega=\omega_{q}-\omega_{h}$ and $\Omega_{T}, \Psi$ as defined above. First, a crucial assumption for the case of the politician which is also derived by the second-order conditions is $\Omega_{T} \Omega>0$, that is, both $\Omega_{T}$ and $\Omega$ have to be of the same sign. This condition is also necessary for an interior solution to emerge. The interpretation of this condition is that the more efficient activity is also the one less prone to rent-seeking. Second, similarly to the case of the citizen and conditional on the satisfaction of the condition $\Omega_{T} \Omega>0$, what is also essential is the interplay between how much human capital and environmental quality is obtained effortlessly, as described by $\Psi$, and what is derived as the result of the fraction of the tax revenue, i.e., $\tau z_{t}$, that the politician will allocate to policies. Analytically, an interior solution $(0<\varphi<1)$ emerges iff $\left.\tau z_{t}\left[1-\omega_{q}\right) \Omega_{T}-A \omega_{q} \Omega\right] / \Omega<$ $\Psi<\left[2 \tau z_{t} \Omega_{T} \Omega+\left[\left(1-\omega_{q}\right) \Omega_{T}-A \omega_{q} \Omega\right]\right] / \Omega$ (i.e., $\left.0<\varphi_{t}<1\right)$. A corner solution will emerge if $\Psi \geq\left[2 \tau z_{t} \Omega_{T} \Omega+\left[\left(1-\omega_{q}\right) \Omega_{T}-A \omega_{q} \Omega\right]\right] / \Omega\left(\varphi_{t}=1\right)$ or $\Psi \leq \tau z_{t}\left[\left(1-\omega_{q}\right) \Omega_{T}-A \omega_{q} \Omega\right] / \Omega\left(\varphi_{t}=0\right)$. Lemma 2 presents the comparative statics with respect to technology and policy parameters.

Lemma 2 Whenever an interior solution emerges, the fraction of public funds directed to education, $\varphi_{t}$,

i. is increasing in $B$ and decreasing in $A$,

ii. decreases (increases) with $\tau$ if $\Omega_{T}>0\left(\Omega_{T}<0\right)$.

Proof The above results can be obtained by taking the derivatives of the interior solution with respect to each parameter.

The first part of Lemma 2 is quite reassuring, since the politician directs resources to the more efficient use. The intuition of the second result is as follows. If abatement is the more effective public activity, $A \omega_{q}>B \omega_{h}$, then the politician allocates less revenue to education as the tax rate increases and vice versa. She does so in order 
to maximize the effectiveness of pubic spending and to increase her own income by minimizing citizens' tax evasion. ${ }^{23}$

Overall, politicians' decision process has many analogies to that of citizens. In allocating public funds between the two activities, she balances her own consumption and her offspring's well-being while taking into account citizens' reaction.

Strategic interactions

As suggested by the two groups' reaction functions, given in Eqs. (8) and (10), each group's expectations regarding the other group's choice are an important determinant of their own decision-making process. Therefore strategic interaction emerges, operating through the common interest for the provision of the public goods. The sign of both reaction functions' slope depends on the sign of the term $\Omega_{T}$. In particular, we can distinguish between two types of interaction.

Lemma $3(A)$ If $\Omega_{T}<0 \Longrightarrow A \omega_{q}<B \omega_{h} \Longrightarrow \frac{\partial z_{t}}{\partial \varphi_{t}}>0, \frac{\partial \varphi_{t}}{\partial z_{t}}>0$, i.e., the politician's and citizen's choices are strategic complements.

(B) If $\Omega_{T}>0 \Longrightarrow A \omega_{q}>B \omega_{h} \Longrightarrow \frac{\partial z_{t}}{\partial \varphi_{t}}<0, \frac{\partial \varphi_{t}}{\partial z_{t}}<0$, i.e., the politician's and citizen's choices are strategic substitutes.

Proof Results (A)-(B) can be obtained by taking the derivative of each group's reaction function, Eqs. (8) and (10), with respect to the other group's decision variable, which yields,

$$
\begin{aligned}
& \frac{\partial z_{t}}{\partial \varphi_{t}}=\frac{-\Psi \Omega_{T}}{2 \tau\left(A \omega_{q}-\varphi_{t} \Omega_{T}\right)^{2}} \gtrless 0 \quad \text { and } \quad \frac{\partial^{2} z_{t}}{\left(\partial \varphi_{t}\right)^{2}}=\frac{-\Psi \Omega_{T}^{2}}{2 \tau\left(A \omega_{q}-\varphi_{t} \Omega_{T}\right)^{3}}<0,(1) \\
& \frac{\partial \varphi_{t}}{\partial z_{t}}=\frac{-\Psi}{2 \tau^{2} z_{t} \Omega_{T}} \gtrless 0, \quad \text { and } \quad \frac{\partial^{2} \varphi_{t}}{\left(\partial z_{t}\right)^{2}}=\frac{\Psi}{2 \tau^{2} z_{t}^{2} \Omega_{T}} \gtrless 0 .
\end{aligned}
$$

Case (A) refers to a situation in which public spending on education is more effective relative to abatement (i.e., $A \omega_{q}<B \omega_{h}$ ), due to either relatively lower rates of rentseeking (i.e., $\omega_{q}<\omega_{h}$ ) and/or due to more efficient technology (i.e., $A<B$ ). In this case, citizens optimally reward the honest attitude of the politicians (where honesty is perceived as allocating more money to the most efficient activity, i.e., education) by evading less (i.e., $\partial z_{t} / \partial \varphi_{t}<0$ ). In case (B) public spending on abatement is more effective relative to education (i.e., $A \omega_{q}>B \omega_{h}$ ), due to either relatively lower rates of rent-seeking (i.e., $\omega_{q}>\omega_{h}$ ) and/or due to more effective technology (i.e., $A>B$ ). In this case, citizens' reaction function is decreasing at a decreasing rate while that of politicians is decreasing at an increasing rate. Citizens optimally declare a lower fraction $z_{t}$ of their income to tax authorities as they observe politicians directing a higher share of public funds to education, which is the less productive activity. ${ }^{24}$ Each

\footnotetext{
23 Citizens optimally choose to pay higher taxes when they observe that the politician directs a higher share of the tax revenue to the most productive activity.

24 Second-order condition of politicians' maximization problem requires that when $\Omega_{T}<0$, then $\Omega<0$, i.e., $\omega_{q}<\omega_{h}$.
} 
group optimally reciprocates to the other group's cheating behavior and thus, defining both groups' strategic choices as cheat - not cheat, they are mutually reinforcing, i.e., they are always strategic complements.

Figure 1 illustrates the two types of strategic interactions. In order to keep the graphical illustration aligned with the mathematical notation, we choose to illustrate the reaction functions in the $\left[z_{t}, \varphi_{t}\right]$ space instead of the [cheat, not cheat] space. Figure 1a illustrates citizens' $\left(R_{\mathrm{c}}\right)$ and politicians' $\left(R_{\mathrm{p}}\right)$ reaction functions when $\Omega_{T}<0$, that is, the case of strategic complementarity. In this case, as politicians allocate more funds to education, which is the more productive activity $\left(A \omega_{q}<B \omega_{h}\right)$, citizens reciprocate by declaring higher part of their income (higher $\varphi_{t}$ leads to higher $z_{t}$ ). Figure $1 \mathrm{~b}$ illustrates both groups' reaction functions when $\Omega_{T}>0$, that is, the case of strategic substitutability. In this case, if politicians choose to invest a higher share of public funds on education (higher $\varphi_{t}$ ), which is the less productive activity $\left(A \omega_{q}>B \omega_{h}\right),{ }^{25}$ thereby signaling a more corrupt behavior, citizens optimally "punish" them by evading a higher fraction of their income (lower $z_{t}$ ). Defining strategic choices as cheat-not cheat, the strategic decisions of the two groups are again mutually reinforcing (higher embezzlement on the part of the politicians, leads to higher evasion on the part of the citizens). This is so despite the fact that both reaction functions are decreasing in the $\left[z_{t}, \varphi_{t}\right]$ space, which implies strategic substitutability.

Figure 1a, b illustrates citizens' $\left(R_{\mathrm{c}}\right)$ and politicians' $\left(R_{\mathrm{p}}\right)$ reaction functions within the feasible range of values $[0,1]$. Three equilibria may occur denoted by points $E_{h}$, $E_{n s}$ and $E_{l}$. Using best reply dynamics we observe that $E_{h}$ and $E_{l}$ are stable equilibria whereas $E_{n s}$ is an unstable equilibrium. Figure 1a depicts the case in which $\Omega_{T}<0$ and $\omega_{q}<\omega_{h}$, that is, education is the more efficient activity and also the one that allows less rent-seeking. $E_{h}$ denotes the high-corruption equilibrium, in which the economy experiences high tax evasion ( $\operatorname{small} z_{t}$ ) and the total tax revenue is being directed to abatement $\left(\varphi_{t}=0\right)$ which allows for maximum rent-seeking. $E_{l}$ denotes the lowcorruption equilibrium where citizens declare a large fraction of their income (high $z_{t}$ ) and a positive part of the tax revenue is directed to the less rent-seeking activity $\left(\varphi_{t}>0\right)$. Figure 1b illustrates the case in which abatement is the more effective activity $\left(\Omega_{T}>0\right)$ and the one that allows less rent-seeking $\left(\omega_{q}>\omega_{h}\right) . E_{l}$ denotes the low-corruption equilibrium where citizens declare a large fraction of their income (high $z_{t}$ ) and all public revenue is directed to the less rent-seeking activity $\left(\varphi_{t}=0\right) . E_{h}$ denotes the high-corruption equilibrium, in which the economy experiences high tax evasion ( to abatement (high $\varphi_{t}$ ) which allows for high rent-seeking.

\subsection{Equilibrium}

The above analysis relies on the implicit assumption that an equilibrium exists. The aim of this section is to establish the conditions under which an equilibrium can be defined.

25 Again, the second-order condition of (9) requires that when $\Omega_{T}>0$, then $\Omega>0$, i.e., $\omega_{h}>\omega_{q}$. 
(a)

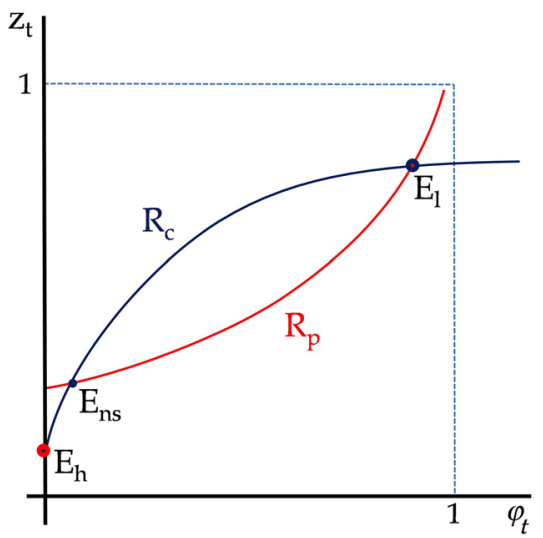

(b)

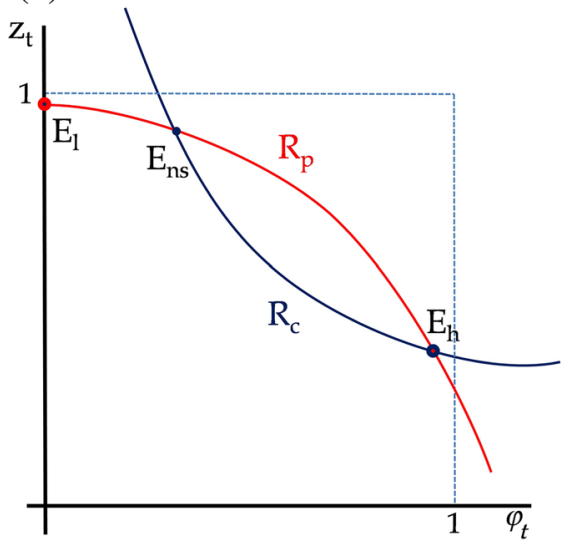

Fig. 1 Citizens' $\left(R_{\mathrm{c}}\right)$ and politicians' $\left(R_{\mathrm{p}}\right)$ reaction function. a if $\Omega_{T}<0$. b if $\Omega_{T}>0$

The literature has examined coordination games in which strategic complementarity exists (for example, Cooper and John 1998; Vives 2005). Games of strategic complementarity are those in which the best response of any player is increasing in the actions of the rival, as is the case for $z_{t}$ and $\varphi_{t}$ when $\Omega_{T}<0$. Strategic complementarity is a condition for the existence of multiple equilibria in symmetric coordination games. ${ }^{26}$ The resulting equilibria are not driven by fundamentals. Instead, they are self-fulfilling and critically depend on one group's anticipation of the other group's behavior.

However, the game analyzed here is not symmetric. Moreover, the boundedness property of the choice set necessitates the consideration of corner solutions. In fact, as we show below, this game does not share many of the properties of games with strategic complementarity. Consider first the following definition of equilibrium:

Definition $1 \mathrm{~A}$ Nash equilibrium in this economy consists of sequences $\left\{c_{i t}\right\}_{t=0}^{\infty},\left\{z_{t}\right\}_{t=0}^{\infty},\left\{\varphi_{t}\right\}_{t=0}^{\infty},\left\{y_{c t}\right\}_{t=0}^{\infty},\left\{h_{t}\right\}_{t=0}^{\infty},\left\{H_{t}\right\}_{t=0}^{\infty},\left\{E_{t}\right\}_{t=0}^{\infty},\left\{Q_{t}\right\}_{t=0}^{\infty},\left\{\Pi_{t}\right\}_{t=0}^{\infty}, i=$ $c, p$, such that, given an initial average stock of human capital $H_{-1}>0$ and an average level of environmental quality $Q_{-1}>0$, in every period $t$,

1. Private citizens choose $z_{t}$ to maximize their utility, taking $\varphi_{t}$ as given.

2. Politicians choose $\varphi_{t}$ to maximize their utility, taking $z_{t}$ as given.

3. The sequences $\left\{h_{t}\right\}_{t=0}^{\infty},\left\{y_{c t}\right\}_{t=0}^{\infty},\left\{Q_{t}\right\}_{t=0}^{\infty},\left\{E_{t}\right\}_{t=0}^{\infty},\left\{\Pi_{t}\right\}_{t=0}^{\infty}$ and $\left\{c_{i t}\right\}_{t=0}^{\infty}$, are determined according to (2), (4), (1.5), (5), (6), (7), and (9).

4. $h_{t}=H_{t}$.

Each group's individual optimization problem is well defined since the utility function is strictly concave and the budget constraint is linear with respect to the relevant decision variable, $z_{t}$ or $\varphi_{t}$. Proposition 2 proves the existence of a pair $\left(z_{t}, \varphi_{t}\right)$ that satisfies Definition 1 in every period. Given the existence of the equilibrium pair $\left(z_{t}, \varphi_{t}\right)$,

26 Notice, however, that also in games with strategic substitutability multiple equilibria may occur as well (Randon 2009). 
we can easily establish the equilibrium values of the remaining variables, following Definition 1.

Proposition 1 An equilibrium pair $\left(z_{t}, \varphi_{t}\right)$ exists for every $t$.

Proof We must establish the existence of a pair $\left(z_{t}, \varphi_{t}\right)$ that satisfies Eqs. (8) and (10) simultaneously. For an arbitrary time period $t$, let $z_{t}=f\left(\varphi_{t}\right)$ denote the solution to the citizen's problem, as described by Eq. (8); for each value of $\varphi_{t}$ there exists a unique value of $z_{t}$. Similarly, let $\varphi_{t}=g\left(z_{t}\right)$ denote the solution to each politician's problem, as described by Eq. (10). Note that both of these functions are continuous (see Eqs. (8), (10)). Thus, the composite function $g \circ f$ from $[0,1]$ to $[0,1]$ is continuous and, by Brower's fixed point theorem, has a fixed point.

Solving the two groups' reaction functions we obtain the following three equilibrium values $\left(z_{i}^{*}, \varphi_{i}^{*}\right), i=1,2,3$ that correspond to the ones described in Fig. 1,

$\begin{array}{ll}z_{1}^{*}=z_{t}\left(\varphi_{t}=0\right) & \varphi_{1}^{*}=\varphi_{t}\left(z_{t}=0\right) \\ z_{2}^{*}=\frac{\sqrt{\Xi}-\sqrt{\Xi-8 \Omega \Psi}}{4 \tau \sqrt{\Xi}} & \varphi_{2}^{*}=\frac{-\left(1-\omega_{q}\right) \Omega_{T}+3 A \omega_{q} \Omega-\sqrt{(\Xi-8 \Omega \Psi) \Xi}}{4 \Omega_{T} \Omega} \\ z_{3}^{*}=\frac{\sqrt{\Xi}+\sqrt{\Xi-8 \Omega \Psi}}{4 \tau \sqrt{\Xi}} \text { or corner }\left(z_{3}^{*}=1\right) & \varphi_{3}^{*}=\frac{-\left(1-\omega_{q}\right) \Omega_{T}+3 A \omega_{q} \Omega+\sqrt{(\Xi-8 \Omega \Psi) \Xi}}{4 \Omega_{T} \Omega} \text { or } \operatorname{corner}\left(\varphi_{3}^{*}=1\right)\end{array}$

where $\Xi=\omega_{h} \omega_{q}(A-B)-\Omega_{T}$. For the nonzero equilibrium values of $z$ and $\varphi$ to be real numbers, it is necessary that $\Xi \geq 0$, and $\Xi-8 \Omega \Psi \geq 0$. The first condition implies that $\frac{B}{A}>\frac{\left(1-\omega_{h}\right) / \omega_{h}}{\left(1-\omega_{q}\right) / \omega_{q}}$, i.e., the ratio of technological efficiency of education to abatement should exceed the ratio of the rates of embezzlement. This condition leads to the following Lemma that restricts attention to the case of strategic complementarity.

Lemma 4 (A) Only the case of strategic complementarity yields real equilibrium solutions.

(B) In the case of strategic complementarity, i.e., $\Omega_{T}<0$, the technology of either activity could be better, i.e., $A \gtrless B$.

Proof Result (A) can be obtained by considering the first condition for real equilibrium solutions, i.e., $\Xi=\omega_{h} \omega_{q}(A-B)-\Omega_{T}>0$. Assume strategic substitutability, i.e., $\Omega_{T}>0$. Then for $\Xi>0$ it must necessarily be that $A>B$. However, $\Xi>0 \Rightarrow$ $B \omega_{h}\left(1-\omega_{q}\right)>A \omega_{q}\left(1-\omega_{h}\right)$. Recall that, from second-order conditions, when $\Omega_{T}>0$, it is necessary that $\Omega>0 \Rightarrow \omega_{q}>\omega_{h}$. Thus, for $\Xi>0$ it is necessary that $B>A$, which contradicts the previous assumption. Therefore, to obtain real solutions we must restrict the analysis to the case of strategic complementarity, i.e., $\Omega_{T}<0$. Result (B) follows again from the restriction that $\Xi>0$. In the case of strategic complementarity, i.e., $\Omega_{T}<0$, this inequality can be satisfied for $A \gtrless B$, as long as $\frac{B}{A}>\frac{\left(1-\omega_{h}\right) / \omega_{h}}{\left(1-\omega_{q}\right) / \omega_{q}}$.

\subsection{Effectiveness of environmental projects}

After establishing the existence of equilibrium and restricting our attention to strategic complementarity we examine the effect of environmental projects on environmental 
quality. For strategic complementarity $\Omega_{T}<0$ and $\Omega<0 \Rightarrow \omega_{q}<\omega_{h}$, which implies that abatement is the more prone to rent-seeking activity. Abatement could be either more or less technologically advanced relative to education, $A \gtrless B$ depending on the $\omega$ 's difference. Under these conditions, does shifting more public funds toward abatement improve environmental quality?

Interestingly, the effect of $\varphi_{t}$ on environmental quality is ambiguous. Direct observation of Eqs. (1.5) and (6) leads to the precocious presumption that an increase in the share of public funds directed toward abatement activities always improves environmental quality. However, this is not always true, since the effectiveness of publicly funded abatement depends on both the levels of rent-seeking and tax evasion and on technological efficiency. Proposition 2 provides an answer to the above stated question.

Proposition 2 Increasing the share of public spending on abatement activities does not necessarily improve environmental quality. The effect depends on both the relative technological efficiency and the rent-seeking opportunities.

Proof From Eqs. (1.5) and (6) we get, $\frac{\partial Q_{t+1}}{\partial\left(1-\varphi_{t}\right)}=-\frac{\partial Q_{t+1}}{\partial \varphi_{t}}=-\left[-\omega_{q} z_{t}+\left(1-\varphi_{t}\right) \frac{\partial z_{t}}{\partial \varphi_{t}}\right]$ $\tau h_{t}$. Since, by Lemma 4, we restrict our attention to strategic complementarity, we have $\frac{\partial z_{t}}{\partial \varphi_{t}}>0$. Thus,

$$
\frac{\partial Q_{t+1}}{\partial\left(1-\varphi_{t}\right)} \lessgtr 0 \quad \text { if }\left(1-\varphi_{t}\right) \frac{\partial z_{t}}{\partial \varphi_{t}} \gtrless \omega_{q} z_{t} .
$$

The above inequality could hold either way, depending on the parameter values. Therefore, for a range of parameter values, $\left(1-\varphi_{t}\right) \frac{\partial z_{t}}{\partial \varphi_{t}}>\omega_{q} z_{t} \Rightarrow \partial Q_{t+1} / \partial\left(1-\varphi_{t}\right)<0$, which implies that increasing public spending on abatement actually decreases environmental quality. Recall that abatement is the high rent-seeking activity $\left(\omega_{q}<\omega_{h}\right)$.

Proposition 2 formally proves that increasing the share of public revenue allocated to the less effective public activity can potentially be detrimental. This result holds for economies with relatively loose enforcement mechanisms, in which reciprocity of corrupt behavior between citizens and politicians is a key determinant of raising tax revenue. Anecdotal evidence cited in Sect. 2 accords with our findings suggesting that a large number of corrupt economies cannot attain improvements in environmental quality even after increasing the funds allocated to environmental projects. Shifting public revenues toward such activities, despite the great potential they present, might prove not only ineffective but also detrimental if $\Omega_{T}<0$ and condition (13) holds.

In terms of policy, our results suggest that an intervention toward decreasing the rate of embezzlement of the public money allocated in environmental policy, is crucial for improving environmental quality. In economies that are highly susceptible to corruption, successful anti-corruption campaigns could play a crucial role in improving the effectiveness of investment in technologically advanced environmental projects.

Although we have treated the rates of embezzlement $1-\omega_{h}$ and $1-\omega_{q}$ as exogenous, institutional changes that reduce rent-seeking opportunities associated with both types of public activity, could substantially increase $\omega_{h}$ and $\omega_{q}$. As far as tax policy is 
concerned, the lower is the tax rate the smaller is tax evasion. The condition $\tau<\frac{1}{2}$ is necessary (but not sufficient) for a nil-evasion $\left(z_{t}=1\right)$ equilibrium to be feasible. Therefore, not very high tax rates coupled with low rent-seeking opportunities can improve the model's outcome. Overall, a society has to ensure the well functioning of the public sector by strengthening its institutions in order to improve the effectiveness of environmental policy.

There are several other mechanisms that could drive this result, e.g., the violation of cost-effectiveness, especially present in large-scale investment projects; Environmental Kuznets Curve which explains that in low-income countries environmental pressure may grow faster than the growth of abatement expenditures; and behavioral mechanisms like the one developed in this paper. In our paper, we shed light on the behavioral mechanism by illustrating how the fact that "corruption may corrupt" can result in lower environmental quality even after allocating funds for abatement. However, in our argument, the technologies involved in each type of spending are also important drivers for the result. Overall, the main result of the paper as described in Proposition 2, reflects the interplay of psychological reasons with cost effectiveness considerations.

In order to obtain analytical results, several restrictive assumptions have been employed in the baseline analysis. The most important one, as mentioned in Sect. 3.1, is the specification of the evolution of environmental quality in Eq. (3). Within this framework, it is evident that the result in Proposition 2 is reinforced by the fact that when spending of abatement activities increases, environmental quality decreases also because human capital, and thus output decreases due to the fact that less resources are devoted to education. Although these assumptions admittedly play a role, the workings of the rent-seeking mechanism is still in place and yields the same result even under a more plausible framework as shown in Appendix 2. Although this framework does not yield analytical solutions, we confirm the result in Proposition 2 using simulations.

\section{Conclusions}

We develop a model that allows us to establish an additional channel via which corruption affects environmental quality. We show that allocating a larger share of public funds to environmental projects that allow politicians to extract high rents could lead to the reduction of funds for these projects, with detrimental effects on environmental quality. Intuitively, there are two effects reinforcing this surprising result. First, when the rate of rent-seeking in environmental projects is high, particularly when the technologies involved are advanced and the investment process is therefore less transparent, a large proportion of public funds are diverted to politicians. Second, the total of available public funds decreases as citizens who observe the poor outcomes of public investment choose to engage in increased tax evasion. This vicious circle of extensive rent-seeking and tax evasion reduces the actual investment in environmental projects.

We use a simplified framework in order to focus on the paper's main results and reveal their principal implications. The model can be extended by introducing more plausible assumptions, but these do not qualitatively affect our results. Such assump- 
tions entail introducing: (i) expected fines for citizens and/or politicians (or being thrown out of office if they embezzle), (ii) different types of expected fines (fines for evading income vs. fines for evading taxes), (iii) endogenous auditing schemes, (iv) more plausible equations of motion for abatement and education. As we show in appendices, our results are robust to the introduction of such modifications.

In light of increased public spending on environmental projects and recent scandals suggesting that public environmental projects can be a rather "profitable" domain for corrupt politicians, our analysis provides interesting policy suggestions. In order to achieve substantial improvements in environmental quality, a society has to strengthen its institutions, reduce rent-seeking opportunities and improve transparency.

Acknowledgements We are thankful to Stanislaw Cichocki, Ryszard Kokoszczynski, Jacob Miethe, Theodore Palivos and two anonymous referees for their feedback. Comments from several participants of EAERE 2012, CRETE 2013 and the 5th International Conference on "The Shadow Economy, Tax Evasion and Informal Labor" were very helpful. Any remaining errors are ours. The final revisions of both the text and empirical strategy of the article were conducted when Athanasios Lapatinas took service at the European Commission's Joint Research Centre. The scientific output expressed does not imply a European Commission policy position. Neither the European Commission nor any person acting on behalf of the Commission is responsible for any use that might be made of this publication.

Open Access This article is distributed under the terms of the Creative Commons Attribution 4.0 International License (http://creativecommons.org/licenses/by/4.0/), which permits unrestricted use, distribution, and reproduction in any medium, provided you give appropriate credit to the original author(s) and the source, provide a link to the Creative Commons license, and indicate if changes were made.

\section{Appendices}

\section{The benchmark model augmented with fines}

In this appendix, we augment the benchmark model with an exogenous probability that the citizen may be audited and fined if he evades. Even in the context of this more complicated model, strategic interactions may always emerge thus giving rise to our basic result. A similar rationale applies for the rest of the assumptions (i)-(iii) mentioned above.

\section{Citizens and Politicians}

Each citizen now solves the following optimization problem,

$$
\begin{aligned}
& \max \quad c_{c t}\left(H_{t+1}+Q_{t+1}\right), \\
& \text { subject to } c_{c t}=\left(1-z_{t} \tau\right) h_{t}-p \tau\left(1-z_{t}\right) h_{t}, \\
& c_{c t} \geq 0, \quad 1 \geq z_{t} \geq 0,
\end{aligned}
$$

To introduce auditing, we now assume that in case he gets caught to evade he gets a fine imposed on evaded income equal to $p \tau\left(1-z_{t}\right) h_{t} . p$ denotes the expected fine. We assume that $p<1$ for evasion to be a fair bet.

For analytical convenience, we assume that the politician remains the same as in the benchmark case, i.e., he is not faced with the threat of being audited. He thus solves the following optimization problem with respect to the fraction of revenue that will 
be allocated in each activity $\varphi_{t}$,

$$
\begin{aligned}
& \max _{c_{p t,} \varphi_{t}} c_{p t}\left(H_{t+1}+Q_{t+1}\right), \\
& \quad \text { subject to } c_{p t}=\left[\left(1-\varphi_{t}\right)\left(1-\omega_{q}\right)+\varphi_{t}\left(1-\omega_{h}\right)\right] \tau z_{t} h_{t} \\
& \quad v c_{p t} \geq 0, \quad 1 \geq \varphi_{t} \geq 0,
\end{aligned}
$$

The Structure of the Economy

The learning technology is described by,

$$
h_{t}=\tilde{H} H_{t-1}-v H_{t-1}+B E_{t-1} \text {. }
$$

Assuming that a fixed fraction of the expected revenue from fines, e.g., 1/2 for simplicity, ${ }^{27}$ returns to the economy, yields that the actual amount spent on education $E_{t}$ is given by,

$$
E_{t}=\varphi_{t} \omega_{h} z_{t} \tau h_{t}+\frac{1}{2} p \tau\left(1-z_{t}\right) h_{t} .
$$

The evolution of environmental quality is described by,

$$
Q_{t}=Q_{0} H_{t-1}-\psi H_{t-1}+A \Pi_{t-1}, \quad Q_{0}>\psi,
$$

Similarly, assuming that the remaining $1 / 2$ of the expected revenue from fines return to abatement spending, $\Pi_{t}$, yields

$$
\Pi_{t}=\left(1-\varphi_{t}\right) \omega_{q} z_{t} \tau h_{t}+\frac{1}{2} p \tau\left(1-z_{t}\right) h_{t}
$$

\subsection{Optimization}

\section{Citizen}

Maximization yields the citizen's choice of $z_{t}$ as function of the model's parameters and the politician's choice of $\varphi$. Thus, we get the citizen's best response function to the politician's choice of $\varphi$,

$$
z_{t}=f\left(\varphi_{t}\right)
$$

The second-order condition, ensuring concavity, requires that $A \omega_{q}-\varphi_{t} \Omega_{T}>(A+$ B) $p / 2$.

\section{Politician}

Maximization yields the politician's choice of $\varphi_{t}$ as function of the model's parameters and the politician's choice of $z_{t}$,

$$
\varphi_{t}=g\left(z_{t}\right)
$$

Second-order conditions require that $\Omega_{T} \Omega>0$.

\footnotetext{
27 Introducing different allocation schemes for the fines is also not crucial for our qualitative results.
} 


\section{Strategic interactions}

As suggested by the two groups' reaction functions, given in Eqs. (1.7) and (1.8), each group's expectations regarding the other group's choice are an important determinant of their own decision-making process. Therefore, strategic interaction emerges, operating through the common interest for the provision of the public goods. The sign of both reaction functions' slope depends on the sign of the term $\Omega_{T}$. In particular, we can distinguish between two types of interaction.

Lemma 1.1 A) If $\Omega_{T}<0 \Longrightarrow A \omega_{q}<B \omega_{h} \Longrightarrow \frac{\partial z_{t}}{\partial \varphi_{t}}>0, \frac{\partial \varphi_{t}}{\partial z_{t}}>0$, i.e., the politician's and citizen's choices are strategic complements.

A) If $\Omega_{T}>0 \Longrightarrow A \omega_{q}>B \omega_{h} \Longrightarrow \frac{\partial z_{t}}{\partial \varphi_{t}}<0, \frac{\partial \varphi_{t}}{\partial z_{t}}<0$, i.e., the politician's and citizen's choices are strategic substitutes.

Proof Results (A)-(B) can be obtained by taking the derivative of each group's reaction function, Eqs. (8) and (10), with respect to the other group's decision variable, which yields,

$$
\begin{aligned}
& \frac{\partial z_{t}}{\partial \varphi_{t}}=\frac{-\Psi \Omega_{T}}{2 \tau\left(A \omega_{q}-\varphi_{t} \Omega_{T}\right)^{2}} \gtrless 0 \text { and } \frac{\partial^{2} z_{t}}{\left(\partial \varphi_{t}\right)^{2}}=\frac{-\Psi \Omega_{T}^{2}}{2 \tau\left(A \omega_{q}-\varphi_{t} \Omega_{T}\right)^{3}}<0, \\
& \frac{\partial \varphi_{t}}{\partial z_{t}}=\frac{-\Psi}{2 \tau^{2} z_{t} \Omega_{T}} \gtrless 0, \text { and } \frac{\partial^{2} \varphi_{t}}{\left(\partial z_{t}\right)^{2}}=\frac{\Psi}{2 \tau^{2} z_{t}^{2} \Omega_{T}} \gtrless 0 .
\end{aligned}
$$

In line with the benchmark model, strategic interactions still arise even after introducing an expected fine for the citizen. The remaining of the analysis is straightforward and similar to the benchmark model. Under the appropriate modifications, our results remain qualitatively unaffected in a model with auditing probabilities.

\section{A more elaborate model}

This section elaborates on assumption (iv) mentioned in Conclusions, i.e., it introduces more elaborate equations of motion as well as a number of additional assumptions that have been simplified in the benchmark model.

\subsection{The basic structure of the model}

The basic structure of the model is identical to the benchmark model. In short, individuals live for two periods, i.e., childhood and adulthood. During the first period of their lives individuals acquire human capital via public schooling, whereas in the second period of their lives they either enter the private market or they become politicians via a random selection process. Their preferences are defined over their own consumption as well as the well-being of their offsprings, which is reflected by the level of human capital they acquire as well as by the quality of environment their receive from their parents. 


\section{Accumulation of human capital}

The learning technology in the public education system is quite similar as in the benchmark model and given by,

$$
h_{t}=V+B E_{t-1} \text {. }
$$

where $t$ denotes time, $h_{t}$ the level of human capital acquired by an individual born at $t-1, E_{t-1}$ the public spending on education in the same period, whereas the parameter $B>0$ measures the efficiency of the public education system. According to this human capital accumulation process, a young agent born in period $t-1$, can acquire, without effort, a minimum level of human capital $V$ of the previous period's accumulated human capital. Contrary to the baseline model, we will assume that the fraction of human capital to be freely obtained does not depend on the human capital of the period $t-1 .^{28}$ As in the benchmark model, the revenue for financing public schooling comes from taxing the economic activity of agents.

\section{Production}

Production uses both human capital and the environment/natural resources as inputs. ${ }^{29}$ That is, we assume that output $y_{c t}$ is, ${ }^{30}$

$$
y_{t}=\Gamma h_{t} Q_{t},
$$

where $\Gamma$ is the production technology. Evidently at the aggregate level, there are increasing returns to scale. This is a simplifying assumption that allows us to make the model slightly more tractable.

\section{Environmental quality}

The evolution of environmental quality is described by

$$
Q_{t}=Q_{t-1}-\psi \Gamma H_{t-1} Q_{t-1}+A \Pi_{t-1}
$$

where $Q_{t-1}$ denotes the state of the environment in the previous period and $\psi$ the extent of environmental degradation due to previous period's aggregate economic activity $\Gamma H_{t-1} Q_{t-1} .^{31}$ The term $A \Pi_{t-1}$ captures the beneficial effect of public spending on abatement on environmental quality, where $A$ is a technological parameter associated with abatement. We assume that $1-\psi \Gamma H_{t-1}>0$. This formulation is rather common in the literature. ${ }^{32}$

\footnotetext{
28 This assumption, coupled with the assumptions of the baseline model, allows us to cover a wide range of equations of motion for human capital and ensure the robustness of our results to alternative specifications.

29 We enrich the production function in order to extend our results to the natural resource strand of the literature and to highlight the robustness of our results to a more elaborate production structure. See for example Gennaioli and Tavoni (2011) for the link between renewable resources and corruption.

30 Since all agents have the same level of human capital and the natural resource is commonly owned, we omit the subscript $i=c, p$ from both variables.

31 This is an additional robustness control to the equation of motion for the environment, in which case in the absence of any economic activity the initial environmental quality $Q_{0}$ would be positive.

32 See for example Economides and Philippopoulos (2008), and John and Pecchenino (1994).
} 


\section{Tax Revenue}

Both types of individuals maximize their utility function as described by Eq. (1) in the basic model. The citizen chooses the fraction $z$ of his income to declare to the tax authority and the politician the fraction $\varphi$ of the total tax revenue to allocate to environmental projects.

The total tax revenue collected in period $t$ is $R_{t}=z_{t} \tau \Gamma h_{t} Q_{t}$. As in the previous model, a fraction $\varphi_{t} z_{t} \Gamma B h_{t} Q_{t}$ of the total tax revenue is earmarked for public education. Since the politician peculates a fraction $1-\omega_{h}$ of $\varphi_{t} R_{t}$ and $1-\omega_{q}$ of $\left(1-\varphi_{t}\right) R_{t}$, of the actual amounts spent on education $E_{t}$ and abatement $\Pi_{t}$ are,

$$
\begin{aligned}
E_{t} & =\varphi_{t} \omega_{h} z_{t} \tau \Gamma h_{t} Q_{t}, \\
\Pi_{t} & =\left(1-\varphi_{t}\right) \omega_{q} z_{t} \tau \Gamma h_{t} Q_{t},
\end{aligned}
$$

respectively. Individual optimization decisions regarding $z_{t}$ and $\varphi_{t}$ affect the sum and the allocation of public spending between education and abatement and consequently the human capital and the state of the environment enjoyed by the next generation.

\subsection{Individual optimization}

\section{Citizen}

Citizens declare a fraction $z_{t}$ of their income $y_{t}$ to the tax authority. Hence, citizens' disposable income is $(1-\tau) z_{t} \Gamma h_{t} Q_{t}+\left(1-z_{t}\right) \Gamma h_{t} Q_{t}=\left(1-z_{t} \tau\right) \Gamma h_{t} Q_{t}$. The individual optimization problem solved by each citizen born in period $t-1$ is,

$$
\max _{c_{c t}, z_{t}} c_{c t}\left[h_{t+1}+Q_{t+1}\right]
$$

subject to

$$
\begin{aligned}
& c_{c t}=\left(1-z_{t} \tau\right) \Gamma h_{t} Q_{t}, \\
& c_{c t} \geq 0, \quad 1 \geq z_{t} \geq 0,
\end{aligned}
$$

where $h, Q, E$ and $\Pi$ are determined by Eqs. (2.1), (2.3) (2.4) and (2.5), taking $\varphi_{t}$, $H_{t}$ and $Q_{t}$ as given.

The first-order condition of the above problem yields citizen's best response function,

$$
z_{t}=f\left(\varphi_{t}\right)=\frac{\left(A \omega_{q}-\varphi_{t} \Omega_{T}\right) \Gamma H_{t} Q_{t}-\Psi_{n}}{2 \tau \Gamma H_{t} Q_{t}\left(A \omega_{q}-\varphi_{t} \Omega_{T}\right)},
$$

where $\Omega_{T}=A \omega_{q}-B \omega_{h}$ and $\Psi_{n}=Q_{t}+V-\psi \Gamma H_{t} Q_{t}$. Concavity holds since $B \omega_{h}-\varphi_{t} \Omega_{T}>0$.

Citizens' reaction function in (2.8) has similar characteristics as the one in the benchmark model (Eq. 8). ${ }^{33}$ However, in this case the reaction function is path depen-

33 The slope of the citizen's reaction function is, $\partial z_{t} / \partial \varphi_{t}=-\Psi_{n} \Omega_{T} / 2 \tau 2 H_{t} Q_{t}\left(A \omega_{q}-\varphi \Omega_{T}\right)^{2}$ and $\partial^{2} z_{t} /\left(\partial \varphi_{t}\right)^{2}=-\Psi_{n} \Omega_{T}^{2} / 2 \tau 2 H_{t} Q_{t}\left(A \omega_{q}-\varphi \Omega_{T}\right)^{3}<0$ since $A \omega_{q}-\varphi \Omega_{T}>0$. Therefore, as in the benchmark model, the sign of citizen reaction function's slope depends on the sign of the term $\Omega_{T}$. 
dent, since $z_{t}$ depends on the level of economic activity, $y_{t}$, that is, on $H_{t}$ and $Q_{t}$. These variables evolve over time until the economy approaches a steady state (whenever a steady state exists) and therefore the optimal strategy is changing over time. It is important to note that at time $t$ the values of $H_{t}$ and $Q_{t}$ have been already determined by the previous generation and therefore each generation treats them as exogenous.

Inspection of Eq. (2.8) reveals that an interior solution $(0<z<1)$ exists iff $(2 \tau-1) \Gamma H_{t} Q_{t}\left(A \omega_{q}-\varphi_{t} \Omega_{T}\right)<\Psi_{n}<\Gamma H_{t} Q_{t}\left(A \omega_{q}-\varphi_{t} \Omega_{T}\right)$. A corner solution $z_{t}=1$ will emerge if the rate of human capital transferred freely to the next generation, $V$, is sufficiently high (low), the rate of degradation of environmental quality, $\psi$, sufficiently low (high) and the rent-seeking rates, $\left(1-\omega_{h}\right)$ and $\left(1-\omega_{q}\right)$, sufficiently high (low). As in the benchmark model, for sufficiently high $\tau\left(\tau>\frac{1}{2}\right)$, the tax evasion rate is never zero, since $z<1$.

Whenever an interior solution emerges, the comparative statics with respect to technology and policy parameters are given in Lemma A.1.

Lemma A.1 Whenever an interior solution emerges, the tax evasion rate $\left(1-z_{t}\right)$ is reduced:

i. the more efficient is the use of tax revenues, (i.e., the higher are A and B),

ii. the lower are the rent-seeking rates (i.e., the higher $\omega_{q}$ and $\omega_{h}$ ), and

iii. the lower is the tax rate, $\tau$.

Proof Results (i)-(iii) can be obtained by taking the derivatives of the interior solution with respect to each parameter.

\section{Politician}

The politician's income is derived solely from peculation of tax revenue and is $\left[\varphi_{t}\left(1-\omega_{q}\right)+\left(1-\varphi_{t}\right)\left(1-\omega_{h}\right)\right] \tau z_{t} \Gamma h_{t} Q_{t}$. The politician's optimization problem is,

$$
\max _{c_{p t}, \mu_{t}} c_{p t}\left[h_{t+1}+Q_{t+1}\right]
$$

subject to

$$
\begin{aligned}
& c_{p t}=\left[\left(1-\varphi_{t}\right)\left(1-\omega_{q}\right)+\varphi_{t}\left(1-\omega_{h}\right)\right] \tau z_{t} \Gamma h_{t} Q_{t}, \\
& c_{p t} \geq 0, \quad 1 \geq \varphi_{t} \geq 0,
\end{aligned}
$$

where $h, Q, E$ and $\Pi$ are determined by Eqs. (2.1), (2.3) (2.4) and (2.5), taking $\varphi_{t}$, $H_{t}$ and $Q_{t}$ as given.

Maximization of the politician's best response function yields,

$$
\varphi_{t}=g\left(z_{t}\right)=\frac{\Omega \Psi_{n}-X \tau z_{t} \Gamma H_{t} Q_{t}}{2 \Omega_{T} \Omega \tau z_{t} \Gamma H_{t} Q_{t}}=-\frac{X}{2 \Omega_{T} \Omega}+\frac{\Psi}{2 \Omega_{T} \tau z_{t} \Gamma H_{t} Q_{t}},
$$

where $\Omega=\omega_{q}-\omega_{h}$ and $X=\left(1-\omega_{q}\right) \Omega_{T}-A \omega_{q} \Omega .^{34}$

\footnotetext{
34 Similar to the benchmark model, for concavity to hold we must have $\Omega_{T} \Omega>0$. The slope of the politician's reaction function is, $\partial \varphi_{t} / \partial z_{t}=-\Psi_{n} / 2 \tau z_{t}^{2} 2 \Gamma H_{t} Q_{t} \Omega_{T}$, with $\partial^{2} \varphi_{t} /\left(\partial z_{t}\right)^{2}=$ $\Psi_{n} / 4 \Gamma \tau z_{t}^{3} 2 H_{t} Q_{t} \Omega_{T}$. The sign of reaction functions' slope depends on the sign of the term $\Omega_{T}$.
} 
For interior solutions $(0<\varphi<1)$ it is required that $\tau z_{t} X \Gamma H_{t} Q_{t} / \Omega<\Psi_{n}<$ $\tau z_{t} \Gamma H_{t} Q_{t}\left(2 \Omega_{T} \Omega+X\right) / \Omega$. On the other hand, corner solutions of directing revenue to a unique policy $\left(\varphi_{t}=0\right.$ and $\varphi_{t}=1$, respectively) emerge depending on the values of $\omega_{h}, \omega_{q}$.

Lemma A.2 Whenever an interior solution emerges, the fraction of public funds directed to education, $\varphi_{t}$,

i. is increasing in $B$, and decreasing in $A$,

iii. the effect of $\tau, \psi$ and $Q_{0}$ and $V$ depends on the sign of $\Omega_{T}$. Specifically

$$
A \omega_{q}-B \omega_{h} \gtrless 0 \Longrightarrow \frac{\partial \varphi_{t}}{\partial \tau} \lessgtr 0, \frac{\partial \varphi_{t}}{\partial \psi} \lessgtr 0, \frac{\partial \varphi_{t}}{\partial Q_{0}} \gtrless 0 \text { and } \frac{\partial \varphi_{t}}{\partial V} \gtrless 0 \text {. }
$$

Overall we observe that despite the fact that our setting is more complex and realistic, the predictions of the model are quite similar with respect to the reaction functions. As was the case with the citizen's reaction function, the politician's reaction function also depends on the realized values of $H_{t}$ and $Q_{t}$ which are predetermined by the previous generation and therefore each generation of politicians treats them as exogenous.

Strategic interactions

Strategic interactions in this setting are similar to the benchmark case. As we show above, the sign of both reaction functions' slope depends on the sign of the term $\Omega_{T}$. Analytically,

$$
\begin{aligned}
& \text { i. } \Omega_{T}<0 \Longrightarrow A \omega_{q}<\beta \omega_{h} \Longrightarrow \frac{\partial z_{t}}{\partial \varphi_{t}}>0, \frac{\partial \varphi_{t}}{\partial z_{t}}>0 \text { i.e., Strategic Complements } \\
& \text { ii. } \Omega_{T}>0 \Longrightarrow A \omega_{q}>\beta \omega_{h} \Longrightarrow \frac{\partial z_{t}}{\partial \varphi_{t}}<0, \frac{\partial \varphi_{t}}{\partial z_{t}}<0 \text { i.e., Strategic Substitutes }
\end{aligned}
$$

yielding similar predictions to the benchmark model. Namely, in the case of strategic complements citizens will choose to "punish" politicians in case they perceive their behavior as corrupt, whereas in the case of strategic substitutes they behave more honestly in order to keep public revenues high.

\subsection{Equilibrium}

The definition of equilibrium remains the same in both models. Each group's individual optimization problem is well defined since its utility function is strictly concave and the budget constraint linear with respect to the relevant decision variable, $z_{t}$ or $\varphi_{t}$. In Proposition A.1, we prove the existence of a pair $\left(z_{t}, \varphi_{t}\right)$ that satisfies Definition 1 in every period, for given values of $H_{t}$ and $Q_{t}$. Given the existence of the equilibrium pair $\left(z_{t}, \varphi_{t}\right)$, we can easily establish the equilibrium values of $H_{t}$ and $Q_{t}$ and subsequently of the remaining variables, following Definition 1 in the main body of the paper.

Proposition A.1 An equilibrium pair $\left(z_{t}, \varphi_{t}\right)$ exists for given values of $H_{t}$ and $Q_{t}$.

Proof We must establish the existence of a pair $\left(z_{t}, \varphi_{t}\right)$ that satisfies Eqs. (2.8) and (2.11) simultaneously. For an arbitrary time period $t$, let $z_{t}=f\left(\varphi_{t}, h_{t}, Q_{t}\right)$ denote the solution to each citizen's problem, as described by Eq. (2.8); for each value of $\varphi_{t}$ there 
exists a unique value of $z_{t}$. Similarly, let $\varphi_{t}=g\left(z_{t}, h_{t}, Q_{t}\right)$ denote the solution to each politician's problem, as described by Eq. (2.11). Note that both of these functions are continuous (see Eqs. 2.8 and 2.11). Thus, the composite function $g \circ f:[0,1] \rightarrow$ $[0,1]$ is continuous and, by Brower's fixed point theorem, has a fixed point.

Solving for the equilibrium values of the model we obtain, ${ }^{35}$

$$
\begin{gathered}
z_{1}^{*}=f^{1}\left(h_{1}^{*}, Q_{1}^{*}\right) \text { or corner }\left(z_{1}^{*}=0\right) \varphi_{1}^{*}=g^{1}\left(h_{1}^{*}, Q_{1}^{*}\right) \text { or corner }\left(\varphi_{1}^{*}=0\right) \\
z_{2}^{*}=f^{2}\left(h_{2}^{*}, Q_{2}^{*}\right) \\
\varphi_{2}^{*}=g^{2}\left(h_{2}^{*}, Q_{2}^{*}\right) \\
z_{3}^{*}=f^{3}\left(h_{3}^{*}, Q_{3}^{*}\right) \text { or corner }\left(z_{3}^{*}=1\right) \varphi_{3}^{*}=g^{3}\left(h_{3}^{*}, Q_{3}^{*}\right) \text { or corner }\left(\varphi_{3}^{*}=0\right)
\end{gathered}
$$

Therefore in terms of strategies there always exists an equilibrium for given values of $h_{t}$ and $Q_{t}$. Since, however, there is a law of motion describing how these two variables evolve, there will be different equilibrium values in each period for $z_{t}$ and $\varphi_{t}$ unless the system approaches a steady state. The dynamics of the model are analyzed in the following subsection.

\subsection{Dynamic behavior of the system of difference equations}

As noted above the stable solutions of the model (if all three are valid) are $\left(z_{1}^{*}, \varphi_{1}^{*}\right)$ and $\left(z_{3}^{*}, \varphi_{3}^{*}\right)$ using best reply dynamics. Since the set $\left(z_{1}^{*}, \varphi_{1}^{*}\right)$ represents a trivial equilibrium of high levels of corruption we will focus on the low-corruption equilibrium $\left(z_{3}^{*}, \varphi_{3}^{*}\right)$. Replacing the equilibrium values for $\left(z_{3}^{*}, \varphi_{3}^{*}\right)$ from Eq. (2.12) into Eqs. (2.1) and (2.3) we obtain the following system of two autonomous nonlinear first-order difference equations

$$
\begin{aligned}
h_{t+1} & =F\left(h_{t}, Q_{t}\right), \\
Q_{t+1} & =G\left(h_{t}, Q_{t}\right) .
\end{aligned}
$$

The dynamics of the system are too complex to be analytically studied. However, we can describe analytically the kind of solution that is desirable in order for our model to be meaningful and provide numerical simulations.

In order to approximate the dynamics of our benchmark model, i.e., a set of equilibrium values for $\left(z_{t}, \varphi_{t}\right)$ that remain unchanged in every period, our system of difference equations must reach a steady state. Therefore, we first assume that the dynamic system has steady-state equilibrium $(\bar{h}, \bar{Q})$. Namely, $\exists(\bar{h}, \bar{Q})$ such that,

$$
\begin{aligned}
\bar{h} & =F(\bar{h}, \bar{Q}), \\
\bar{Q} & =G(\bar{h}, \bar{Q}) .
\end{aligned}
$$

A Taylor expansion of the system around the steady-state values $(\bar{h}, \bar{Q})$, yields:

$$
\begin{aligned}
h_{t+1} & =F\left(h_{t}, Q_{t}\right) \\
& =F(\bar{h})+F_{h}(\bar{h}, \bar{Q})\left(h_{t}-\bar{h}\right)+F_{Q}(\bar{h}, \bar{Q})\left(Q_{t}-\bar{Q}\right)+R_{1}+R_{2},
\end{aligned}
$$

35 We omit analytical expression due to their complexity. 


$$
\begin{aligned}
Q_{t+1} & =G\left(h_{t}, Q_{t}\right) \\
& =G(\bar{Q})+G_{h}(\bar{h}, \bar{Q})\left(h_{t}-\bar{h}\right)+G_{Q}(\bar{h}, \bar{Q})\left(Q_{t}-\bar{Q}\right)+R_{1}+R_{2},
\end{aligned}
$$

where $F_{h}(\bar{h}, \bar{Q})$ and $G_{h}(\bar{h}, \bar{Q})$ are the partial derivatives of the functions $F\left(h_{t}, Q_{t}\right)$ and $G\left(h_{t}, Q_{t}\right)$ evaluated at $(\bar{h}, \bar{Q})$ and $R_{1}$ and $R_{2}$ are the error terms which are very small in the neighborhood of $(\bar{h}, \bar{Q})$ and have little influence on the behavior of the system. Thus, the nonlinear system is being approximated, locally (around the steadystate equilibrium) by the linear system:

$$
\left[\begin{array}{l}
h_{t+1} \\
Q_{t+1}
\end{array}\right]=\left[\begin{array}{c}
F(\bar{h}) \\
G(\bar{Q})
\end{array}\right]+\left[\begin{array}{cc}
F_{h}(\bar{h}, \bar{Q}) & F_{Q}(\bar{h}, \bar{Q}) \\
G_{h}(\bar{h}, \bar{Q}) & G_{Q}(\bar{h}, \bar{Q})
\end{array}\right]\left[\begin{array}{c}
h_{t}-\bar{h} \\
Q_{t}-\bar{Q}
\end{array}\right],
$$

where,

$$
J(\bar{h}, \bar{Q})=\left[\begin{array}{ll}
F_{h}(\bar{h}, \bar{Q}) & F_{Q}(\bar{h}, \bar{Q}) \\
G_{h}(\bar{h}, \bar{Q}) & G_{Q}(\bar{h}, \bar{Q})
\end{array}\right],
$$

is the Jacobian matrix evaluated at the steady-state equilibrium. $Q_{o}$ and $h_{0}$ denote the initial values for $h_{t}$ and $Q_{t}$ and are exogenously given.

If all eigenvalues of $J(\bar{h}, \bar{Q})$ have moduli strictly less than $1,(\bar{h}, \bar{Q})$ is asymptotically stable (a sink). If at least one eigenvalue of $J(\bar{h}, \bar{Q})$ has modulus greater than 1 , then $(\bar{h}, \bar{Q})$ is unstable (a source). If the eigenvalues of $J(\bar{h}, \bar{Q})$ are all inside the unit circle, but at least one is on the boundary (has modulus 1$)$, then $(\bar{h}, \bar{Q})$ may be stable, asymptotically stable or unstable. Therefore, we take the following steps: Test whether our system approaches the steady state $(\bar{h}, \bar{Q})$. For this steady state to be a feasible solution, the dynamics of the system must satisfy the limitations of the model, namely concavity and the implied values $\bar{z} \leq 1$ and $\bar{\varphi} \leq 1$. Also the dynamics of the system must be characterized by stability, i.e., the eigenvalues must be inside the unit circle.

If the above restrictions hold, then we are fully able to describe the behavior of the equilibrium values of $\left(z^{*}, \varphi^{*}\right)$ in every period of the model up to the steady state. It is important to have a stable steady state since otherwise $h_{t}$ and $Q_{t}$ grow without limits, and taking into account that $\frac{\partial z^{*}}{\partial h_{t}}>0$ and $\frac{\partial z^{*}}{\partial Q_{t}}>0$, the value of $z_{t}$ will increase continuously reaching eventually unity.

\subsection{Numerical approximations}

The enriched model closely follows the benchmark model up to the point where we obtain the reaction functions. However, due to the system of nonlinear difference equations, it quickly becomes rather complicated. Therefore, we resort to numerical simulations in order to illustrate our results.

The model uses a number of parameters, namely $A, B, \Gamma, \tau, \omega_{h}, \omega_{q}, V$, and $\psi$. As the above analysis reveals, the most important term driving our results is $\Omega_{T}=$ $A \omega_{q}-\beta \omega_{h}$, determining the type of strategic interaction between the two groups of agents.

Evidently, the model is a rough approximation of reality; therefore, it is hard to clarify what values of the parameters can be considered as "realistic". Still though 


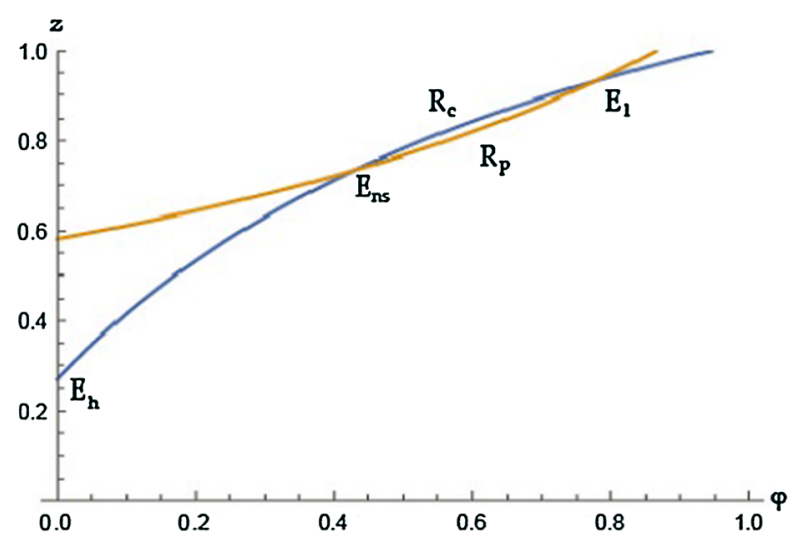

Fig. 2 Numerical reaction functions - the parameter values are $A=5, B=9, \omega_{h}=0.6, \omega_{q}=0.5, \tau=$ $0.3, v=0.2, \psi=0.4, \Gamma=4, Q_{0}=0.11 H_{0}=0.28$.

with respect to tax evasion there is some evidence that in the Western developed countries the rates of tax evasion are estimated around 5\%-25\% of potential tax revenue (Feige 1989; Pyle 1989; Thomas 1992) while for developing countries higher rates may appear (Tanzi and Shome 1994). For the year 1988 in the USA, the TCMP has estimated that only a $53 \%$ of taxpayers paid their taxes correctly. Of course, noncompliance does not apply to all these cases, since a $7 \%$ has overpaid its taxes while a part of the remaining $40 \%$ has underpaid due to errors that result from the complicated procedure involved. According to Franzoni (1998), the federal income tax gap of the USA had been estimated for 1998 at $17 \%$.

Concerning the values of $\omega_{h}$ and $\omega_{q}$, there is much evidence that different allocations of public budget are associated with different rent-seeking rates. Mauro (1998) finds evidence that public expenditure on high-technology goods is associated with higher rent-seeking due to low detectability and the same goes for military expenditure. On the other hand, education and health sectors involve more transparent expenditure and are thus associated with lower rent-seeking rates. The range of these rates varies enormously depending on the quality of institutions in each country. The rates of embezzlement could be as low as $0.5-2 \%$ for developed countries and could be as high as $30-50 \%$ for developing countries. Since our model primarily targets to account for abatement in highly corrupt countries we will allow for high embezzlement rates (i.e., $\omega_{h}$ and $\omega_{q}$, can be as low as $\left.0.5-0.6\right)$. Tax rates vary between $0.25-0.55$.

As to the parameters $A, B$, and $\Gamma$ it is harder to pin down which range of values would be plausible. Therefore we will focus on their between ratio as implied by our model, namely $A, B$ and $\Gamma>0$ and $A \omega_{q}<B \omega_{h}$ for strategic complementarity which is the case we analyze. For the value of $v$, there is also no evidence, still though it is plausible to assume that it will take rather small values, well below unity (e.g., Ceroni 2001) takes values of $v$ as low as $v=0.2$ ).

Having pinned down the range of parameter values and having imposed the restrictions mentioned earlier, namely concavity, strategic complementarity and an asymptotically stable steady state we obtain a number of feasible steady states. Figure 2 illustrates a numerical example with specific values of the model's parameters. 
In this example, in line with the predictions of our baseline model, there are two stable and one unstable $\left(z_{2}^{*}, \varphi_{2}^{*}\right)=(0.734,0.430)$ equilibria emerging. The two stable equilibria are the high $\left(z_{1}^{*}, \varphi_{1}^{*}\right)=(0.268,0)$ and the low $\left(z_{3}^{*}, \varphi_{3}^{*}\right)=(0.931,0.776)$ corruption equilibria. In the high-corruption equilibrium $\left(z_{1}^{*}, \varphi_{1}^{*}\right)$ the politician allocates the entire tax revenue to the corrupt activity, i.e., abatement and the citizen declares a small potion of his income. In the low-corruption equilibrium she allocates a high portion of public fund to education and the citizen reciprocates by declaring almost all his income.

\section{The simplified model}

Consider a perfectly competitive overlapping generations economy where economic activity extends over infinite discrete time and a single good is being produced in the private sector. Individuals live for two periods, i.e., childhood and adulthood. During the first period of their life individuals acquire human capital via public schooling, whereas during adulthood they either enter the productive sector of the economy or they become politicians via a random selection process. Their preferences are defined over their own consumption, as well as over the well-being of their offspring, which is captured by the level of human capital and the quality of the environment they bequeath to them. For expositional convenience, we assume that the two public goods are abatement and education. As mentioned above, the only crucial point is that spending on each public good provides differential opportunities for rent-seeking.

\subsection{The structure of the economy}

In each period $t$, a generation of individuals of measure one is born. Each individual has a single parent. During childhood individuals acquire human capital and for simplicity, it is assumed that they are not economically active; their consumption is incorporated into their parents' consumption. During adulthood individuals are economically active allocating their income between current consumption and their offsprings' well-being. Formally, individuals born at $t-1$, during their adulthood (i.e., in period $t$ ), maximize the following utility function,

$$
u_{t}=c_{t}\left(h_{t+1}+Q_{t+1}\right) \text {, }
$$

where $c_{t}$ denotes the adults' level of consumption, $h_{t+1}$ their offspring's human capital and $Q_{t+1}$ the environmental quality handed over to their offsprings. The presence of the offspring's human capital level and environmental quality in the parental utility function captures the adult agent's vested interest in publicly funded education and environmental (abatement) projects. ${ }^{36}$

\footnotetext{
36 The introduction of a parameter measuring the relative strength of the altruistic motive associated with each activity would further complicate our analysis without providing additional insights. Similarly, assuming an additive type of utility function (with respect to $Q_{t}$ and $H_{t}$ ) is also for the sake of analytical convenience.
} 
Following the literature, we assume that the learning technology is described by, ${ }^{37}$

$$
h_{t}=\tilde{H} H_{t-1}-v H_{t-1}+B E_{t-1},
$$

where $t$ denotes time, $h_{t}$ the level of human capital acquired by an individual born at $t-1, H_{t-1}$ the average stock of human capital present in the economy at time $t-1$, and $E_{t-1}$ the public spending on education in the same period. According to this human capital accumulation process, a young agent born in period $t-1$, can pick up a fraction $\tilde{H} \in[0,1]$ of the existing (average) level of human capital $H_{t-1}$ without any cost, simply by observing what the previous generation does. Existing human capital depreciates at a rate $v \in[0,1]$. To further enhance an agent's human capital requires the allocation of public resources to education, $E_{t-1}$. The parameter $B>0$ measures the efficiency of the public education system. Therefore, the overall level of human capital reflects the effect of both societal knowledge and formal education.

The evolution of environmental quality is described by,

$$
Q_{t}=Q_{0} H_{t-1}-\psi H_{t-1}+A \Pi_{t-1}, \quad Q_{0}>\psi,
$$

where $Q_{0} H_{t-1}$ denotes the initial state of environmental quality $Q_{0}$, conditional on the level of production $H_{t-1}$ in period $t-1$. The term $\psi H_{t-1}$ captures the environmental damage caused by production in the previous period (we assume that production employs only human capital), and $\psi$ is a technological parameter that can be interpreted as the rate of environmental degradation per unit of output. The term $A \Pi_{t-1}$ captures the beneficial effect of publicly funded abatement activities on environmental quality, where $A$ is a technological parameter.

\subsection{Citizens and politicians}

Individuals entering into adulthood, via a random process, are either employed in the productive sector (hereafter called citizens) or they become politicians. Individual preferences are independent of occupation. For analytical convenience, it is assumed that there is a continuum of agents within each group that is normalized to unity. In terms of notation, the subscripts $c$ and $p$ are used to denote variables that are related to citizens and politicians, respectively.

Citizens produce a single good consumed by both groups. In the baseline version of the model, we assume that production employs only human capital, while the environment does not contribute to the production process. Thus, using the appropriate normalization of units, each citizen's output $y_{t}$ is, ${ }^{38}$

$$
y_{t}=h_{t} \text {. }
$$

\footnotetext{
37 See for example De Gregorio and Kim (2000) and Ceroni (2001).

38 Since all agents have the same level of human capital we omit the subscript $i=c, p$.
} 
It follows that the aggregate production function is linear to the aggregate level of human capital, that is, $Y_{t}=H_{t}$. Notice that since the size of each group is normalized to one, $h_{t}=H_{t}$ and thus, $y_{t}=Y_{t}$.

Taxing citizen's income at the rate $\tau$, assumed to be exogenous and time-invariant, provides the necessary revenue for the provision of public education and abatement. Citizens have the option to evade a fraction of their taxes at the rate $z_{t}$. In order to simplify the analysis, we define $g_{t}=z_{t} \tau$, which is the tax rate the consumer pays. Thus, consumers instead of optimally choosing the tax evasion rate $z_{t}$ they now choose the optimal tax rate.

For the sake of brevity, it is assumed that the citizen's declaration is never audited; consequently, tax evasion does not involve any risk. Although tax payments are implicitly assumed to be a voluntary contribution, citizens' free riding incentive is partly mitigated by their altruistic concerns about their offspring's education and environmental quality and thus, they always declare a positive fraction of their income, as will be illustrated in a following section. ${ }^{39}$

Politicians do not participate in the production process. Instead their role lies in determining the allocation of public funds between education (a fraction $\varphi$ of the total tax revenue) and abatement. The politician receives a fixed income, as a reimbursement for her service, which for analytical convenience and without loss of generality is assumed to be equal to zero. Moreover, she has the option to embezzle part of the tax revenue as a means of supplementing her income. ${ }^{40}$ Specifically, she can embezzle a fraction $\left(1-\omega_{q}\right)$ of public funds directed to abatement while we assume that funds directed to education involve completely transparent transactions, such as wages, and thus the rent-seeking rate is zero. It is assumed that $\omega_{q}$ is exogenously given, strictly positive and less than one. The magnitude of $\omega_{q}$ depends on the economy's institutional, political and social characteristics. In the context of the paper, we do not endogenize the choice of $\omega_{q}$ as it extends beyond the scope of our analysis. ${ }^{41}$ What is crucial for our analysis is the plausible assumption that different sectors of the economy manifest differential rent-seeking rates (in our case education is associated with a zero rent-seeking rate).

We further assume that the politician is never investigated and hence peculation does not involve any risk. Given that the politician has zero income, she will always embezzle a fraction of the tax revenue. However, the politician's concern over her offspring's well-being ensures that she will always have an incentive to avoid directing

\footnotetext{
39 Still though, citizens find it optimal to evade a fraction of their income. Alternatively, we could construct a model where there are two different types of citizens and two different types of politicians who differ in their corruption attitude (e.g., differential tax morale). This would allow us to address the issue of free riding more explicitly. Such an approach though, extends beyond the scope of our analysis, weakening the main argument that higher investment in abatement may result in the deterioration of environmental quality. The issue of free riding, which it could affect the quantitative characteristics of our findings, is not the driving force behind our results.

40 Assuming a positive reimbursement for the politician (either a constant amount, or a fraction of the tax revenue) reduces the magnitude of the incentive to embezzle public funds, but it does not qualitatively affect the results. As long as there is an incentive to embezzle part of the funds, the results of the model remain robust to this assumption.

41 There is an extensive literature focusing on the implications of rent-seeking rates (see, e.g., Krueger 1974; Park et al. 2005; Angelopoulos et al. 2009).
} 
the entire amount of public funds to abatement, i.e., to the activity associated with a positive rent-seeking rate.

Since only citizens are being taxed, the total tax revenue $R_{t}$, collected in period $t$, is the fraction of the aggregate income that is being taxed, i.e., $R_{t}=g_{t} h_{t}$. In the absence of embezzlement by the politician, a fraction $\varphi_{t} g_{t} h_{t}$ of the tax revenue would be earmarked for education and the remaining $\left(1-\varphi_{t}\right) g_{t} h_{t}$ for abatement.

However, the politician peculates a fraction of this revenue. In particular, she peculates a fraction $1-\omega_{q}$ of the tax revenue earmarked for abatement, and thus, the actual amount spent on education $E_{t}$ and on abatement $\Pi_{t}$ is,

$$
\begin{aligned}
E_{t} & =\varphi_{t} g_{t} h_{t}, \\
\Pi_{t} & =\left(1-\varphi_{t}\right) \omega_{q} g_{t} h_{t},
\end{aligned}
$$

respectively. Overall, individuals' decisions at time $t$ regarding the level of tax evasion and the allocation of public funds, have an indirect effect on the aggregate level of both public goods which is enjoyed by the offspring of both types of individuals. Therefore, citizens' decisions are indirectly affected by the decisions of the politicians and vice versa, driven by the altruistic incentives of both groups, thus suggesting the presence of strategic interactions in their decision-making process.

\subsection{Optimization}

\section{Citizen}

As discussed above, citizen's preferences are defined over his own consumption in period $t, c_{c t}$, and his offspring's well-being in the next period $t+1$ as affected by the level of human capital they will acquire $h_{t+1}$, and the quality of the environment $Q_{t+1}$. His gross income in period $t$ is $h_{t}$, which is taxed at the exogenous rate $\tau$. The citizen chooses the optimal tax rate that will be imposed on their income, $g_{t}$ and thus they will pay income tax $g_{t} h_{t}$, which implicitly determines consumption at time $t$ and the level of public goods transferred to his offspring. We assume that citizens cannot directly observe the politicians' ability to embezzle part of the total tax revenue. He indirectly observes politicians actions via the environmental and educational quality of the next period, which is crucial for the well-being of the citizen's offspring. Therefore, each citizen solves the following optimization problem,

$$
\begin{gathered}
\max _{c_{c t}, g_{t}} c_{c t}\left(H_{t+1}+Q_{t+1}\right), \\
\text { subject to } c_{c t}=\left(1-g_{t}\right) h_{t}, \\
c_{c t} \geq 0, \quad \tau \geq g_{t} \geq 0,
\end{gathered}
$$

where $h, Q, E$ and $\Pi$ are determined by Eqs. (3.2), (3.3) and (3.5).

Maximization yields the citizen's choice of $z_{t}$ as function of the model's parameters and the politician's choice of $\varphi$. Thus, we get the citizen's best response function to the politician's choice of $\varphi$,

$$
g_{t}=f\left(\varphi_{t}\right)=\frac{\left(A \omega_{q}-\varphi_{t} \Omega_{T}\right)-\Psi}{2\left(A \omega_{q}-\varphi_{t} \Omega_{T}\right)},
$$


where $\Omega_{T}=A \omega_{q}-B$ and $\Psi=Q_{0}+\tilde{H}-\psi-v$. The second-order condition, ensuring concavity, requires that $A \omega_{q}-\varphi_{t} \Omega_{T}>0$, which always holds since $\varphi_{t} \leq 1$.

Furthermore, an interior solution $\left(\tau>g_{t}>0\right)$ exists iff $(1-2 \tau)\left(A \omega_{q}-\varphi_{t} \Omega_{T}\right)<$ $\Psi<A \omega_{q}-\varphi_{t} \Omega_{T}$. On the contrary, a corner solution will emerge if $\Psi \geq\left(A \omega_{q}-\right.$ $\left.\varphi_{t} \Omega_{T}\right)\left(g_{t}=0\right)$ or $\Psi \leq(1-2 \tau)\left(A \omega_{q}-\varphi_{t} \Omega_{T}\right)\left(g_{t}=\tau\right)$.

Comparative statics suggest that when $v$ and $\psi$ increase, i.e., when there is extensive depreciation of environmental quality and human capital, citizens choose a higher tax rate. On the contrary when $Q_{0}$ and $\tilde{H}$ increase, then $g_{t}$ decreases suggesting that citizens choose a lower optimal tax rate. Lemma 1 presents the comparative statics with respect to technology and policy parameters.

Lemma 3.1 Whenever an interior solution emerges, the optimal tax rate $\left(g_{t}\right)$ increases:

i. the more efficient is the use of tax revenues, (i.e., the higher are A and B), and

ii. the lower is the rent-seeking rate (i.e., $\omega_{q}$ ).

Proof The above results can be obtained by taking the derivatives of the interior solution with respect to each parameter.

\section{Politician}

Since we have assumed that individual preferences are independent of occupation, politician's preferences are also given by (3.1). Assuming zero income from other sources, the politician derives income only via the embezzlement of public funds. Taking as given the rent-seeking rate associated with abatement $1-\omega_{q}$, she determines the allocation of public revenues between education and abatement in order to maximize her utility. Her income equals the amount of the funds embezzled from abatement activities, i.e., $\left(1-\varphi_{t}\right)\left(1-\omega_{q}\right) g_{t} H_{t}$. The politician solves the following optimization problem with respect to the fraction of revenue that will be allocated in each activity $\varphi_{t}$,

$$
\begin{aligned}
& \max _{c_{p t,} \varphi_{t}} c_{p t}\left(H_{t+1}+Q_{t+1}\right), \\
& \quad \text { subject to } c_{p t}=\left(1-\varphi_{t}\right)\left(1-\omega_{q}\right) g_{t} h_{t}, \\
& c_{p t} \geq 0, \quad 1 \geq \varphi_{t} \geq 0,
\end{aligned}
$$

where $h, Q, E$ and $\Pi$ are determined by Eqs. (3.2), (3.3), (3.5) and (3.6).

The first-order condition of (3.9) yields the politician's best response function to citizen's choice of $z_{t}$,

$$
\varphi_{t}=g\left(z_{t}\right)=\frac{\Psi \Omega-g_{t}\left[\left(1-\omega_{q}\right) \Omega_{T}-A \omega_{q} \Omega\right]}{2 g_{t} \Omega_{T} \Omega}
$$

where $\Omega=\omega_{q}-1$ and $\Omega_{T}, \Psi$ as defined above. Second-order conditions require that $\Omega_{T} \Omega>0$, i.e., since $\Omega<0$ we must have $\Omega_{T}<0$ as well. Furthermore, an interior solution $(0<\varphi<1)$ emerges iff $\left.g_{t}\left[1-\omega_{q}\right) \Omega_{T}-A \omega_{q} \Omega\right] / \Omega<\Psi<$ $g_{t}\left[2 \Omega_{T} \Omega+\left[\left(1-\omega_{q}\right) \Omega_{T}-A \omega_{q} \Omega\right]\right] / \Omega$ (i.e., $\left.0<\varphi_{t}<1\right)$. A corner solution will emerge if $\Psi \geq g_{t}\left[2 \Omega_{T} \Omega+\left[\left(1-\omega_{q}\right) \Omega_{T}-A \omega_{q} \Omega\right]\right] / \Omega\left(\varphi_{t}=1\right)$ or $\Psi \leq$ 
$g_{t}\left[\left(1-\omega_{q}\right) \Omega_{T}-A \omega_{q} \Omega\right] / \Omega\left(\varphi_{t}=0\right)$. Crucially, note that further elaborating on the corner solution given by the inequality $\Psi \geq g_{t}\left[2 \Omega_{T} \Omega+\left[\left(1-\omega_{q}\right) \Omega_{T}-A \omega_{q} \Omega\right]\right] / \Omega$ $\left(\varphi_{t}=1\right)$ yields $\Psi \geq-g_{t} B$. Thus, the solution $\varphi_{t}=1$ can never occur, i.e., politicians would never direct all the budget to the zero rent-seeking activity

Lemma 2 presents the comparative statics with respect to technology and policy parameters.

Lemma 3.2 Whenever an interior solution emerges, the fraction of public funds directed to education, $\varphi_{t}$, is increasing in $B$ and decreasing in $A$.

Proof The above results can be obtained by taking the derivatives of the interior solution with respect to each parameter.

Overall, politicians' decision process has many analogies to that of citizens. In allocating public funds between the two activities, she balances her own consumption and her offsprings' well-being while taking into account citizens' reaction.

Strategic interactions

As suggested by the two groups' reaction functions, given in Eqs. (3.8) and (3.10), each group's expectations regarding the other group's choice are an important determinant of their own decision-making process. Therefore strategic interaction emerges, operating through the common interest for the provision of the public goods. The sign of both reaction functions' slope depends on the sign of the term $\Omega_{T}$. Given that $\Omega_{T}<0$ as suggested by the politician's maximization we have the following type of interaction.

Lemma 3.3 Since $\Omega_{T}<0 \Longrightarrow A \omega_{q}<B \omega_{h} \Longrightarrow \frac{\partial z_{t}}{\partial \varphi_{t}}>0$, $\frac{\partial \varphi_{t}}{\partial z_{t}}>0$, i.e., the politician's and citizen's choices are strategic complements.

Proof To obtain this result, we take the derivative of each group's reaction function, Eqs. (3.8) and (3.10), with respect to the other group's decision variable, which yields,

$$
\begin{aligned}
& \frac{\partial z_{t}}{\partial \varphi_{t}}=\frac{-\Psi \Omega_{T}}{2 \tau\left(A \omega_{q}-\varphi_{t} \Omega_{T}\right)^{2}}>0 \quad \text { and } \quad \frac{\partial^{2} z_{t}}{\left(\partial \varphi_{t}\right)^{2}}=\frac{-\Psi \Omega_{T}^{2}}{2 \tau\left(A \omega_{q}-\varphi_{t} \Omega_{T}\right)^{3}}<0, \\
& \frac{\partial \varphi_{t}}{\partial z_{t}}=\frac{-\Psi}{2 \tau^{2} z_{t} \Omega_{T}}>0, \quad \text { and } \quad \frac{\partial^{2} \varphi_{t}}{\left(\partial z_{t}\right)^{2}}=\frac{\Psi}{2 \tau^{2} z_{t}^{2} \Omega_{T}}<0 .
\end{aligned}
$$

This result refers to a situation in which public spending on education is more effective relative to abatement (i.e., $A \omega_{q}<B$ ), due either to the fact that education spending is a non-rent-seeking activity while abatement is (i.e., $\omega_{q}<1$ ) and/or due to more efficient technology (i.e., $A<B$ ). In this case, citizens optimally reward the honest attitude of the politicians (where honesty is perceived as allocating more money to the most efficient activity, i.e., education) by evading less (i.e., $\partial z_{t} / \partial \varphi_{t}<0$ ). Each group optimally reciprocates to the other group's cheating behavior and thus we define both groups' strategic choices as cheat - not cheat. 
Fig. 3 Citizens' $\left(R_{\mathrm{C}}\right)$ and politicians' $\left(R_{\mathrm{p}}\right)$ reaction function

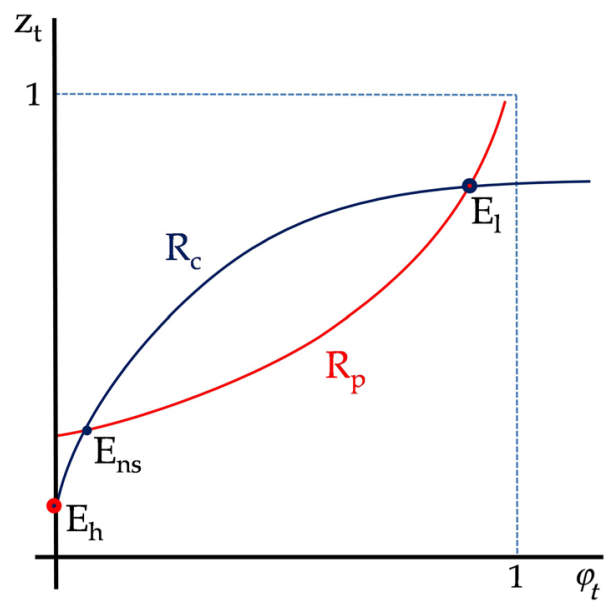

Figure 3 illustrates the strategic complementarity. In order to keep the graphical illustration aligned with the mathematical notation, we choose to illustrate the reaction functions in the $\left[z_{t}, \varphi_{t}\right]$ space instead of the [cheat, not cheat] space. Figure 3 illustrates citizens' $\left(R_{\mathrm{C}}\right)$ and politicians' $\left(R_{\mathrm{p}}\right)$ reaction functions when $\Omega_{T}<0$, that is, the case of strategic complementarity. In this case, as politicians allocate more funds to education, which is the more productive activity $\left(A \omega_{q}<B\right)$, citizens reciprocate by declaring higher part of their income (higher $\varphi_{t}$ leads to higher $z_{t}$ ).

Figure 3 illustrates citizens' $\left(R_{\mathrm{c}}\right)$ and politicians' $\left(R_{\mathrm{p}}\right)$ reaction functions within the feasible range of values $[0,1]$. Three equilibria may occur denoted by points $E_{h}, E_{n s}$ and $E_{l}$. Using best reply dynamics we observe that $E_{h}$ and $E_{l}$ are stable equilibria whereas $E_{n s}$ is an unstable equilibrium. Analytically, in the case in which $\Omega_{T}<0$ and $\omega_{q}<1$, education is the more efficient activity and also the one that allows for zero rent-seeking. $E_{h}$ denotes the high-corruption equilibrium, in which the economy experiences low optimal tax rate (small $g_{t}$ ) and the total tax revenue is being directed to abatement $\left(\varphi_{t}=0\right)$ which allows for maximum rent-seeking. $E_{l}$ denotes the low-corruption equilibrium where citizens choose a high optimal tax rate (high $g_{t}$ ) and a positive part of the tax revenue is directed to the no rent-seeking activity $\left(\varphi_{t}>0\right)$.

\subsection{Equilibrium}

The above analysis relies on the implicit assumption that an equilibrium exists. The aim of this section is to establish the conditions under which an equilibrium can be defined.

The literature has examined coordination games in which strategic complementarity exists (for example, Cooper and John 1998; Vives 2005). Games of strategic complementarity are those in which the best response of any player is increasing in the actions of the rival, as is the case for $z_{t}$ and $\varphi_{t}$ when $\Omega_{T}<0$. Strategic complemen- 
tarity is a condition for the existence of multiple equilibria in symmetric coordination games. $^{42}$

The resulting equilibria are not driven by fundamentals. Instead, they are selffulfilling and critically depend on one group's anticipation of the other group's behavior.

However, the game analyzed here is not symmetric. Moreover, the boundedness property of the choice set necessitates the consideration of corner solutions. In fact, as we show below, this game does not share many of the properties of games with strategic complementarity. Consider first the following definition of equilibrium:

Definition 1 A Nash equilibrium in this economy consists of sequences $\left\{c_{i t}\right\}_{t=0}^{\infty},\left\{z_{t}\right\}_{t=0}^{\infty},\left\{\varphi_{t}\right\}_{t=0}^{\infty},\left\{y_{c t}\right\}_{t=0}^{\infty},\left\{h_{t}\right\}_{t=0}^{\infty},\left\{H_{t}\right\}_{t=0}^{\infty},\left\{E_{t}\right\}_{t=0}^{\infty},\left\{Q_{t}\right\}_{t=0}^{\infty},\left\{\Pi_{t}\right\}_{t=0}^{\infty}, i=$ $c, p$, such that, given an initial average stock of human capital $H_{-1}>0$ and an average level of environmental quality $Q_{-1}>0$, in every period $t$,

1. Private citizens choose $z_{t}$ to maximize their utility, taking $\varphi_{t}$ as given.

2. Politicians choose $\varphi_{t}$ to maximize their utility, taking $z_{t}$ as given.

3. The sequences $\left\{h_{t}\right\}_{t=0}^{\infty},\left\{y_{c t}\right\}_{t=0}^{\infty},\left\{Q_{t}\right\}_{t=0}^{\infty},\left\{E_{t}\right\}_{t=0}^{\infty},\left\{\Pi_{t}\right\}_{t=0}^{\infty}$ and $\left\{c_{i t}\right\}_{t=0}^{\infty}$, are determined according to (3.2), (3.4), (3.3), (3.5), (3.6), (3.7), and (3.9).

4. $h_{t}=H_{t}$.

Each group's individual optimization problem is well defined since the utility function is strictly concave and the budget constraint is linear with respect to the relevant decision variable, $z_{t}$ or $\varphi_{t}$. Proposition 1 proves the existence of a pair $\left(z_{t}, \varphi_{t}\right)$ that satisfies Definition 1 in every period. Given the existence of the equilibrium pair $\left(z_{t}, \varphi_{t}\right)$, we can easily establish the equilibrium values of the remaining variables, following Definition 1.

Proposition 1 An equilibrium pair $\left(z_{t}, \varphi_{t}\right)$ exists for every $t$.

Proof We must establish the existence of a pair $\left(z_{t}, \varphi_{t}\right)$ that satisfies Eqs. (3.8) and (3.10) simultaneously. For an arbitrary time period $t$, let $z_{t}=f\left(\varphi_{t}\right)$ denote the solution to the citizen's problem, as described by Eq. (3.8); for each value of $\varphi_{t}$ there exists a unique value of $z_{t}$. Similarly, let $\varphi_{t}=g\left(z_{t}\right)$ denote the solution to each politician's problem, as described by Eq. (3.10). Note that both of these functions are continuous (see Eqs. (3.8) and (3.10)). Thus, the composite function $g \circ f$ from $[0,1]$ to $[0,1]$ is continuous and, by Brower's fixed point theorem, has a fixed point.

Solving the two groups' reaction functions we obtain the following three equilibrium values $\left(z_{i}^{*}, \varphi_{i}^{*}\right), i=1,2,3$ that correspond to the ones described in Figure 3 ,

$$
\begin{array}{ll}
z_{1}^{*}=z_{t}\left(\varphi_{t}=0\right) & \varphi_{1}^{*}=\varphi_{t}\left(g_{t}=0\right) \\
z_{2}^{*}=\frac{\sqrt{\Xi}-\sqrt{\Xi-8 \Omega \Psi}}{4 \tau \sqrt{\Xi}} & \varphi_{2}^{*}=\frac{-\left(1-\omega_{q}\right) \Omega_{T}+3 A \omega_{q} \Omega-\sqrt{(\Xi-8 \Omega \Psi) \Xi}}{4 \Omega_{T} \Omega} \\
z_{3}^{*}=\frac{\sqrt{\Xi}+\sqrt{\Xi-8 \Omega \Psi}}{4 \tau \sqrt{\Xi}} \text { or corner }\left(g_{3}^{*}=\tau \tau\right) & \varphi_{3}^{*}=\frac{-\left(1-\omega_{q}\right) \Omega_{T}+3 A \omega_{q} \Omega+\sqrt{(\Xi-8 \Omega \Psi) \Xi}}{4 \Omega_{T} \Omega}
\end{array}
$$

\footnotetext{
42 Notice, however, that also in games with strategic substitutability multiple equilibria may occur as well (Randon 2009).
} 
where $\Xi=\omega_{q}(A-B)-\Omega_{T}$. For the nonzero equilibrium values of $z$ and $\varphi$ to be real numbers, it is necessary that $\Xi \geq 0$, and $\Xi-8 \Omega \Psi \geq 0$. The first condition implies that $\omega_{q}<1$ which holds always. The second condition is satisfied as well since $\Omega<0$. We thus obtain the following Lemma.

Lemma 3.4 A) The case of strategic complementarity yields real equilibrium solutions.

B) In the case of strategic complementarity, i.e., $\Omega_{T}<0$, the technology of either activity could be better, i.e., $A \gtrless B$.

Proof Result (A) is obtained by considering that both conditions $\Xi \geq 0$, and $\Xi-$ $8 \Omega \Psi \geq 0$ hold in the case of strategic complements. Result (B) follows again from the restriction that $\Xi>0$. In the case of strategic complementarity, i.e., $\Omega_{T}<0$, this inequality can be satisfied for $A \gtrless B$, as long as $\frac{B}{A}>\omega_{q}$.

\subsection{Effectiveness of environmental projects}

After establishing the existence of equilibrium and restricting our attention to strategic complementarity we examine the effect of environmental projects on environmental quality. For strategic complementarity $\Omega_{T}<0$ and $\Omega<0$ since $\omega_{q}<1$, which implies that abatement is the rent-seeking activity. Abatement could be either more or less technologically advanced relative to education, i.e., $A \gtrless B$. Under these conditions, does shifting more public funds toward abatement improves environmental quality?

Interestingly, the effect of $\varphi_{t}$ on environmental quality is ambiguous. Direct observation of Eqs. (3.3) and (3.6) leads to the precocious presumption that an increase in the share of public funds directed toward abatement activities always improves environmental quality. However, this is not always true, since the effectiveness of publicly funded abatement depends on both the levels of rent-seeking and tax evasion (manifested in the choice of the optimal tax rate) and on technological efficiency. Proposition 2 provides an answer to the above-stated question.

Proposition 2 Increasing the share of public spending on abatement activities, does not necessarily improve environmental quality. The effect depends on both the relative technological efficiency and the rent-seeking opportunities. spending on abatement activities, does not necessarily improve environmental quality. The effect depends on both the relative technological efficiency and the rent-seeking opportunities.

Proof From Eqs. (3.3) and (3.6) we get, $\frac{\partial Q_{t+1}}{\partial\left(1-\varphi_{t}\right)}=-\frac{\partial Q_{t+1}}{\partial \varphi_{t}}=-\left[-\omega_{q} g_{t}+\left(1-\varphi_{t}\right)\right.$ $\left.\omega_{q} \frac{\partial g_{t}}{\partial \varphi_{t}}\right] h_{t}$. Since, by Lemma 4 , we restrict our attention to strategic complementarity, we have $\frac{\partial g_{t}}{\partial \varphi_{t}}>0$. Thus,

$$
\frac{\partial Q_{t+1}}{\partial\left(1-\varphi_{t}\right)} \lessgtr 0 \text { if }\left(1-\varphi_{t}\right) \frac{\partial g_{t}}{\partial \varphi_{t}} \gtrless g_{t} \text {. }
$$

The above inequality could hold either way, depending on the parameter values. Therefore, for a range of parameter values, $\left(1-\varphi_{t}\right) \frac{\partial g_{t}}{\partial \varphi_{t}}>g_{t} \Rightarrow \partial Q_{t+1} / \partial\left(1-\varphi_{t}\right)<0$, 
which implies that increasing public spending on abatement actually decreases environmental quality.

Proposition 2 formally proves that increasing the share of public revenue allocated to the less effective public activity can potentially be detrimental.

\section{References}

Andvig, J. C., \& Moene, K. O. (1990). How corruption may corrupt. Journal of Economic Behavior and Organization, 13, 63-76.

Angelopoulos, K., Philippopoulos, A., \& Vassilatos, V. (2009). The social cost of rent seeking in Europe. European Journal of Political Economy, 25, 280-299.

Antoniou, F., Hatzipanayotou, P., \& Koundouri, P. (2014). Tradable permits vs ecological dumping when governments act non-cooperatively. Oxford Economic Papers, 66, 188-208.

Bhattarai, M., \& Hamming, M. (2001). Institutions and the Environmental Kuznets curve for deforestation: A cross-country analysis for Latin America, Africa and Asia. World Development, 29, 995-1010.

Bimonte, S. (2002). Information access, income distribution and the Environmental Kuznets Curve. Ecological Economics, 41, 145-156.

Blackman, A., \& Kildegaard, A. (2010). Clean technological change in developing country industrial clusters: Mexican leather tanneries. Environmental Economics and Policy Studies, 12(3), 115-132.

Bornstein, N., \& Lanz, B. (2008). Voting on the environment: Price or ideology? Evidence from Swiss referendums. Ecological Economics, 67(3), 430-440.

Brock, W. A., \& Taylor, M. S. (2005). Economic growth and the environment: A review of theory and empirics. In Handbook of economic growth (Vol. 1, pp. 1749-1821). Amsterdam: Elsevier.

Carlsson, F., \& Johansson-Stenman, O. (2000). Willingness to pay for improved air quality in Sweden. Applied Economics, 32(6), 661-669.

Caselli, F. (1999). Technological revolutions. American Economic Review, 89(1), 78-102.

Ceroni, C. B. (2001). Poverty traps and human capital accumulation. Economica, 68, 203-219.

Cooper, R., \& John, A. (1998). Coordinating coordination failures in Keynesian models. The Quarterly Journal of Economics, 103, 441-464.

Cropper, M. L., Evans, W. N., Berard, S. J., Ducla-Soares, M. M., \& Portney, P. R. (1992). The Determinants of pesticide regulation: A statistical analysis of EPA decision making. Journal of Political Economy, 100, 175-97.

Damania, R. (2002). Environmental controls with corrupt bureaucrats. Environment and Development Economics, 7, 407-427.

Damania, R., Fredriksson, P. G., \& Mani, M. (2004). The persistence of corruption and regulatory failures: Theory and evidence. Public Choice, 121, 363-390.

Dasgupta, S., Hettige, H., \& Wheeler, D. (2000). What improve Environmental Compliance? Evidence from Mexican Industry. Journal of Environmental Economics and Management, 39(1), 39-66.

De Gregorio, J., \& Kim, S. (2000). Credit markets with differences in abilities: Education, distribution, and growth. International Economic Review, 41, 579-607.

Delavallade, C. (2006). Corruption and distribution of public spending in developing countries. Journal of Economics and Finance, 30, 222-239.

Economides, G., \& Philippopoulos, A. (2008). Growth enhancing policy is the means to sustain the environment. Review of Economic Dynamics, 11, 207-219.

Farzin, Y. H., \& Bond, C. A. (2006). Democracy and environmental quality. Journal of Development Economics, 81(1), 213-235.

Feige, E. L. (1989). The underground economies. Tax evasion and information distortion. Cambridge: Cambridge University Press.

Fershtman, C., Murphy, K. M., \& Weiss, Y. (1996). Social status, education, and growth. Journal of Political Economy, 104(1), 108-132.

Franzoni, L. A. (1998). Independent auditors as fiscal gatekeepers. International Review of Law and Economics, 18, 365-384.

Fredriksson, P. G., List, J. A., \& Millimet, D. L. (2003). Bureaucratic corruption, environmental policy and inbound US FDI: Theory and evidence. Journal of Public Economics, 87, 1407-1430. 
Fredriksson, P. G., Neumayer, E., Damania, R., \& Gates, S. (2005). Environmentalism, democracy, and pollution control. Journal of Environmental Economics and Management, 49(2), 343-365.

Gächter, S., \& Schulz, J. F. (2016). Intrinsic honesty and the prevalence of rule violations across societies. Nature, 531(7595), 496.

Galor, O., \& Moav, O. (2000). Ability-biased technological transition, wage inequality, and economic growth. The Quarterly Journal of Economics, 115(2), 469-497.

Gangadharan, L. (2006). Environmental compliance by firms in the manufacturing sector in Mexico. Ecological Economics, 59(4), 477-486.

Gennaioli, C., \& Tavoni, M. (2011). Clean or dirty energy: Evidence on a renewable energy resource curse (No. 63.2011). Nota di lavoro//Fondazione Eni Enrico Mattei: Energy: Resources and Markets.

Goetz, S., Debertin, D., \& Pagoulatos, A. (1998). Human capital, income, and environmental quality: A state-level analysis. Agricultural and Resource Economics Review, 27(2), 200-208.

Grimaud, A., \& Tournemaine, F. (2007). Why can an environmental policy tax promote growth through the channel of education? Ecological Economics, 62(1), 27-36.

Gupta, S., Sharan R., \& de Mello L. (2000). Corruption and Military Spending. IMF working papers 00/23, International Monetary Fund.

Helland, E. A. (1998). The enforcement of pollution control laws: Inspections, violations, and self-reporting. Review of Economics and Statistics, 80, 141-153.

Hessami,Z. (2010). Corruption and the composition of public expenditures: Evidence from OECD countries. MPRA Paper 25945.

Ikefuji, M., \& Horii, R. (2007). Wealth heterogeneity and escape from the poverty-environment trap. Journal of Public Economic Theory, 9(6), 1041-1068.

John, A., \& Pecchenino, R. (1994). An overlapping generations model of growth and the environment. The Economic Journal, 104(427), 1393-1410.

Kahn, M. E. (2002). Demographic change and the demand for environmental regulation. Journal of Policy Analysis and Management, 21(1), 45-62.

Krueger, A. O. (1974). The political economy of the rent-seeking society. American Economic Review, 64, 291-303.

Lan, J., \& Munro, A. (2013). Environmental compliance and human capital: Evidence from Chinese industrial firms. Resource and Energy Economics, 35(4), 534-557.

Lisciandra, M., \& Migliardo, C. (2017). An empirical study of the impact of corruption on environmental performance: Evidence from panel data. Environmental and Resource Economics, 68(2), 297-318.

Litina, A., \& Palivos, T. (2013). Explicating corruption and tax evasion: Reflections on Greek tragedy. Working Paper.

Lopez, R., \& Mitra, S. (2000). Corruption, pollution and the Kuznets environment curve. Journal of Environmental Economics and Management, 40, 137-150.

Manderson, E., \& Kneller, R. (2012). Environmental regulations, outward FDI and heterogeneous firms: Are countries used as pollution havens? Environmental \& Resource Economics European Association of Environmental and Resource Economists, 51(3), 317-352.

Mauro, P. (1998). Corruption and the composition of government expenditure. Journal of Public Economics, 69(2), 263-279.

Panayotou, T. (1997). Demystifying the environmental Kuznets curve: Turning a black box into a policy tool. Environment and Development Economics, 2, 465-484.

Pargal, S., \& Wheeler, D. (1996). Informal regulation of industrial pollution in developing countries: Evidence From Indonesia. Journal of Political Economy, 104(6), 1314-1327.

Park, H., Philippopoulos, A., \& Vassilatos, V. (2005). Choosing the size of the public sector under rent seeking from state coffers. European Journal of Political Economy, 21, 830-850.

Pashigian, P. (1985). Environmental regulation: Whose self-interests are being protected? Economic Inquiry, 23, 551-84.

Pyle, D. J. (1989). Tax evasion and the black economy. London: The Macmillan Press.

Raffin, N. (2010). Education and the political economy of environmental protection. unpublished

Randon, E. (2009). Multiple equilibria with externalities. Discussion Papers 04/09, Department of Economics, University of York.

Shalvi, S. (2016). Behavioural economics: Corruption corrupts. Nature, 531(7595), 456.

Stathopoulou, E., \& Varvarigos, D. (2013). Corruption, entry and pollution. Department of Economics discussion paper no. 13/21, University of Leicester.

Tanzi, V., \& Davoodi, H. (1997). Corruption, public investment, and growth. IMF Working Paper. 
Tanzi, V., \& Davoodi, H. (2000). Corruption, growth and public Finances. IMF Working Paper.

Tanzi, V., \& Shome, P. (1994). A primer on tax evasion. Bulletin for International Fiscal Documentation, $48,328-337$.

Thalmann, P. (2004). The public acceptance of green taxes: 2 million voters express their opinion. Public Choice, 119(1-2), 179-217.

Thomas, J. J. (1992). Informal economic activity. LSE Handbooks in Economics. London: Harvester Wheatsheaf.

Torras, M., \& Boyce, J. K. (1998). Income, inequality and pollution: Reassessment of the Environmental Kuznets Curve. Ecological Economics, 25, 147-160.

Vives, X. (2005). Complementarities and games: New developments. Journal of Economic Literature, 43, 437-479. 